\title{
IRON DEFICIENCY AND IRON OVERLOAD
}

\author{
BY \\ R. SEPHTON SMITH* \\ From the Department of Pediatrics, University of Southern California and Children's Hospital of Los Angeles, U.S.A. $\dagger$
}

(RECEIVED FOR PUBLICATION MARCH 29, 1965)

Iron is essential to most, if not all, living organisms, and the higher animals and man have employed it for many purposes essential to life. The readiness with which iron undergoes oxidation and reduction is utilized in many of the enzymes of electron transport, and in a number of other enzymes whose function is not understood. Furthermore, the combination of iron with porphyrin and protein leads to complexes that have the property of binding large amounts of oxygen in a readily reversible fashion. Haemoglobin and myoglobin are complexes of this nature, which serve the function of oxygen transport and storage. About three-quarters of the iron in a normal man (between $4 \mathrm{~g}$. and $5 \mathrm{~g}$.) is incorporated in circulating haemoglobin. Less than $5 \%$ is present in myoglobin, various enzymes, or in transport in the plasma. The remainder, about $20 \%$ of the total, is present in the tissue stores, much of it as the iron-protein complex ferritin (Drabkin, 1951). Very little iron is excreted, as the iron from broken-down aged red cells is returned to the marrow for re-use in haemoglobin synthesis. The iron content of the body is achieved during periods of growth, and maintained thereafter at a steady level, through control of the amount absorbed. As the amount of iron utilized in haemoglobin synthesis is so much greater than the quantity of new iron absorbed, it is perhaps not surprising that iron deficiency is so common. It is the most frequent cause of anaemia, and the most important deficiency state in countries with good economic means. Iron deficiency is particularly common in early infancy, as the requirements of rapid growth exceed the infant's capacity to absorb enough iron from food. Iron in excess is toxic: acute iron poisoning follows ingestion of large amounts of iron salts, and is one of the most common

\footnotetext{
* Formerly Research Fellow in Haematology, The Hospital for Sick Children, Great Ormond Street, London.

† Postal address: 4614 Sunset Boulevard, Los Angeles, California 90027, U.S.A.
}

and serious forms of poisoning seen in young children. The progressive deposition of iron in the tissues from excess intestinal absorption or after repeated transfusions leads eventually to impaired organ function. In children chronic iron overload is increasingly seen, now that the availability of blood transfusion and improved medical care have prolonged the survival in conditions such as thalassaemia, and the hypoplastic and aplastic anaemias. The development of new iron-chelating agents raises the possibility of removing excess iron in these conditions, and offers specific therapy for acute iron poisoning. In this review, the aspects of iron deficiency and iron excess of special interest to the paediatrician will be considered in relation to our basic concepts of iron metabolism.

\section{Iron Absorption}

The classic observations of McCance and Widdowson (1937) that the ability to excrete iron was very severely limited, led to the concept that the absorptive process must be of paramount importance in regulating the body's content of iron. Our knowledge of the mechanism of iron absorption and of the factors that control it is incomplete. Chemical balance studies of iron absorption are notoriously difficult for technical reasons, and most of our knowledge has come from studies using tracer doses of radioactive isotopes. Such studies limit our observations to the absorption of a measured dose of a single labelled substance. Their applicability to the absorption of iron from a whole meal, or a complete diet, is doubtful. The iron in food exists in a number of different chemical forms, each of which may be absorbed by a different process. Some food iron is present in the ionized form (Ascham, Speirs, and Maddox, 1938; Bergeim and Kirsch, 1949), but there will also be varying amounts of tightly-complexed iron, such as haemoglobin, 
TABLE 1

FACTORS INFLUENCING IRON ABSORPTION

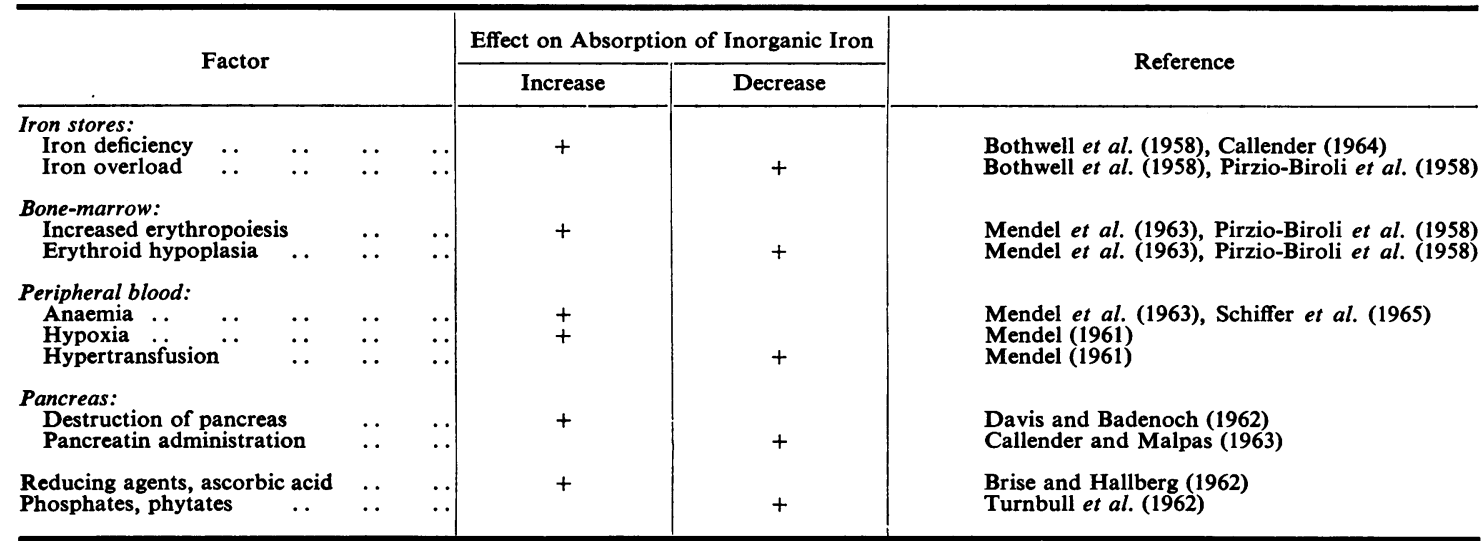

myoglobin, and ferritin, in meats and liver. Iron can be absorbed at any level when placed in direct contact with the gut mucosa (Valquist, Neander, and Neander, 1945), but absorption is largely confined to the duodenum and upper small bowel when iron salts are given by mouth (Brown and Justus, 1958). The amount of iron absorbed seems to depend on a number of unrelated factors (Table 1).

Type of Iron. Ferrous iron is absorbed to a greater extent than the ferric form, when placed in a gut loop (Groen, Van Den Broeck, and Veldman, 1947). When given by mouth, ferric iron is absorbed to a greater extent, though still not as well as the ferrous form (Brise and Hallberg, 1962): the use of a ferrous complexing agent blocks the absorption of both forms (Venkatachalam, Brading, George, and Walsh, 1956), so it appears that ionized iron is reduced before its absorption. Furthermore, the absorption of iron salts can be increased by adding reducing substances such as ascorbic acid (Moore, Bierman, Minnich, and Arrowsmith, 1940; Brise and Hallberg, 1962). Absorption may be reduced by binding substances such as phosphates and phytates (McCance, Edgecomb, and Widdowson, 1943; Turnbull, Cleton, and Finch, 1962). When iron salts are given with food, absorption is reduced (Pirzio-Biroli, Bothwell, and Finch, 1958), and if baked in bread, they are less than half as well absorbed as when given alone (Steinkamp, Dubach, and Moore, 1955). Studies of the absorption of haemoglobin, in which the iron is present as a complex with porphyrin, show that in a dose of $5 \mathrm{mg}$. this type of iron is about half as well absorbed as ferrous sulphate (Callender, 1964). Moreover, the absorption of this type of iron is not enhanced by ascorbic acid, or blocked by the presence of a meal or phytate (Turnbull et al., 1962). This finding is of great interest and suggests that the mechanism of absorption of haemoglobin iron may differ fundamentally from the absorption of iron salts. It is possible that the iron in porphyrin complexes is absorbed as such, without conversion into free ionized iron. Sanford (1961) demonstrated that less than $12 \%$ of the iron in liver or haemoglobin could be split off by peptic or tryptic digestion. On the other hand, patients with iron-deficiency anaemia may absorb as much as $68 \%$ of a dose of haemoglobin iron (Callender, 1964).

Amount of Iron. The quantity of iron administered to some extent determines the amount absorbed. Studies using graded doses of radioiron have shown that at each increasing dose level, although the proportion of the dose absorbed was reduced, the actual amount of iron absorbed increased (Smith and Pannacciulli, 1958). About $50 \%(0.05 \mathrm{mg}$.) of a dose of $0.1 \mathrm{mg}$. ferrous iron is absorbed by a normal man, compared with $5-10 \%$ (5-10 mg.) of a dose of $100 \mathrm{mg}$. (Bothwell and Finch, 1962 , p. 98).

Effect of Gastric Secretion. The site of maximal iron absorption has focused attention on the possible role of gastric and duodenal juice in the regulation of iron absorption. It is well known that iron absorption is decreased after partial gastrectomy (Baird, Podmore, and Wilson, 1957; Stevens, Pirzio-Biroli, Harkins, Nyhus, and Finch, 1959), but this may not be the result of achlorhydria. Although Goldberg, Lochhead, and Dagg (1963) found decreased iron absorption in anaemic patients 
with achlorhydria, Moore and Dubach (1956) were unable to increase it in such patients by the administration of hydrochloric acid. It may be that anatomical continuity of the stomach and intestine, rather than the presence of acid, is necessary for adequate absorption of iron.

Effect of Pancreatin. Recent work suggests that pancreatic secretions may have a much more important role in the regulation of iron absorption than was formerly realized. In 1935 Taylor, Stiven, and Reid showed that iron deposition developed rapidly following ligation of the pancreatic duct in cats. More recently, Davis and Badenoch (1962) showed that iron absorption was significantly increased in 6 patients with severe chronic pancreatitis. In one patient, iron absorption was reduced by the administration of pancreatic extract. Further studies have shown that the administration of pancreatic extracts will reduce the absorption of iron in patients with cirrhosis of the liver and haemochromatosis (Biggs and Davis, 1963; Callender and Malpas, 1963). It has also been shown that children with cystic fibrosis, treated by pancreatic extracts, absorb iron poorly and show evidence of iron deficiency (Smith, 1964a). The mechanism of this action of pancreatin is not understood. It is not likely to be due to a direct absorptive effect, as it has been shown that pancreatin can absorb only negligible amounts of iron (Biggs and Davis, 1963). Furthermore the inhibitory effect on iron absorption is found with haemoglobin iron as well as with iron salts (Callender and Malpas, 1963).

Mucosal Factors. The transfer of iron from the gut lumen is effected through the mucosal cell as an active metabolic process (Dowdle, Schachter, and Schenker, 1960). It appears that the entry of iron into a mucosal cell stimulates the production of the protein apoferritin which then combines with iron to form ferritin (Gabrio and Salomon, 1950; Granick, 1946). This has led to much speculation as to whether ferritin accumulation inhibits or facilitates iron absorption. In early experiments with dogs, it was found that iron absorption was much depressed when a loading dose had been given several hours previously (Hahn, Bale, Ross, Balfour, and Whipple, 1943), and the concept of the 'mucosal block' was formed in which it was suggested that the mucosal cells, when saturated with ferritin, had the ability to prevent the absorption of further iron. This old concept, however, does not stand examination in the light of modern experience. The massive absorption in acute iron poisoning shows that the block is, at best, incomplete, and more recent experiments have shown that when iron is infused continuously, or in sequential doses, iron absorption in appreciable amounts may continue for 4 to 6 hours (Brown, Dubach, and Moore, 1958; Hallberg and Sölvell, 1960). However, there is good evidence that the mucosal cell does play an active part in the regulation of iron absorption. Recent autoradiographic studies (Conrad and Crosby, 1963) suggest that absorption of iron proceeds in two distinct stages. Following the initial rapid uptake of iron by the mucosal cell, ferritin is formed, after which the iron may enter the blood stream, or remain, if not needed, to be shed into the gut as the mucosal cell desquamates. The role of the mucosal cell in iron absorption is reviewed in detail by Crosby (1963). The regulation of transfer of iron from the mucosal cell into the circulation is not well understood. At least three factors, or combinations of them, seem to be involved: the size of the iron stores, the rate of erythropoiesis, and the haemoglobin level in the blood.

Size of Iron Stores. There is good evidence that the size of the iron stores influences the amount of iron absorbed. Absorption is increased in irondeficiency anaemia, or when the stores are diminished, and iron overload leads to a reduction in iron absorption (Bothwell, Pirzio-Biroli, and Finch, 1958; Callender, 1964; Pirzio-Biroli et al., 1958; Moore, 1955). Similar variations were seen in a study in which iron absorption was measured in normal subjects, in whom the iron stores were varied over a period of three years (Pirzio-Biroli and Finch, 1960). From a normal mean absorption of $6 \%$ of a tracer dose of iron added to food, absorption was reduced to $3 \%$ when the stores were increased by $1.5 \mathrm{~g}$., and conversely was increased to about $20 \%$ after iron depletion. These variations were not dependent on the level of haemoglobin, plasma iron, or transferrin. The results suggest that throughout life iron absorption may be modified in a way to maintain optimal body stores. During periods of growth, or after blood loss, absorption may be augmented until adequate stores have been achieved. At the present time, the mechanism by which the level of body iron stores can influence the absorption of iron is obscure. It is evidently not accomplished through changes in the degree of saturation of the plasma transferrin. which have been found to have no influence on iron absorption (Wheby and Jones, 1963).

Erythropoiesis and Anaemia. There is a wealth of evidence that iron absorption varies with alterations in the rate of erythropoiesis: increased erythropoiesis is accompanied by increased iron absorption, and conversely when erythropoiesis is reduced or 
abolished, iron absorption is diminished. The evidence is well reviewed by Bothwell and Finch (1962, p. 108). This view is supported by the finding that iron overload frequently develops in patients with chronic haemolytic anaemias of various aetiology. Unfortunately, many of the patients and experimental models studied have additionally some degree of anaemia or iron-loading or both, so that it is not always possible to conclude that an alteration in iron absorption noted is solely or mainly the consequence of an alteration in erythropoiesis. Mendel (1961) and Mendel, Weiler, and Mangalik (1963) studied this problem in mice where erythropoiesis had been abolished by splenectomy and administration of radioactive strontium. It was, therefore, possible to study independently the effects of changes in the rate of erythropoiesis and in the haemoglobin level. It was found that iron absorption was enhanced not only by increased erythropoiesis, but also by anaemia or hypoxia not associated with increased erythropoiesis. The increase in iron absorption following erythropoietin administration was also clearly shown to be due to increased erythropoiesis: no effect was seen in animals without erythropoiesis. A recent study of iron absorption in aregenerative anaemia (Schiffer, Price, and Cronkite, 1965) has also clearly demonstrated that anaemia, even in the presence of decreased erythropoiesis, may be associated with increased absorption of iron.

In summary, there is good evidence that the size of the iron stores has an important role in regulating iron absorption in health, and in promoting increased absorption in iron deficiency. The pancreatic secretions may also play an important part in preventing excess absorption of iron. In many haemolytic and refractory anaemias, anaemia and sometimes increased erythropoiesis might be expected to increase iron absorption, and increased iron stores to reduce it. The balance of these opposing forces must vary, though most of the evidence suggests that the inhibiting effect of increased iron stores can be overcome, so that these patients develop a progressive overloading with iron.

\section{Iron Excretion}

Although iron is often referred to as a 'one-way' substance, minute amounts are lost in the urine, faeces, sweat, and exfoliated cells. Many attempts to measure these losses by chemical methods have given erroneously high values, as it is almost impossible to prevent external contamination of the body surface. By the use of radioactive iron, the total loss from all these sources has been estimated to be between $0.5 \mathrm{mg}$. and $1.0 \mathrm{mg}$. daily (Dubach, Moore, and Callender, 1955). A second isotopic method has been to label the total body iron, and follow the radioactivity of the red cell mass for several years (Finch, 1959). By this method an average total daily iron loss of $0.6 \mathrm{mg}$. was calculated for normal men. It seems reasonable to conclude that adult men will lose on average slightly less than $1 \mathrm{mg}$. daily. The figure will be higher for women during the child-bearing years, due to additional losses from menstruation and pregnancy. No data are available for children, but it may be assumed that boys of all ages and girls in the years preceding the onset of menstruation will not lose more iron than adult men, and will probably in fact lose considerably less, perhaps in proportion to their surface area. Newborn infants appear to be an exception, and may lose up to $3 \mathrm{mg}$. daily in the stools during the first few days of life (Cavell and Widdowson, 1964). This interesting finding might be explained by failure of the immature newborn liver to conserve some of the iron from red-cell breakdown. It is not yet known at what age these high faecal losses of iron cease.

In iron-deficient subjects, the loss of iron is reduced (Dubach et al., 1955). Patients with iron loading might be expected to excrete more iron than normal men, due to the increased iron content of exfoliated cells and secretions, but this has not yet been proved. However, a daily iron loss of about $4 \mathrm{mg}$. was estimated for a single patient (Crosby, Conrad, and Wheby, 1963).

\section{Iron Nutrition in Childhood}

When growth has ceased, adults remain in iron balance by absorbing from food sufficient iron to replace normal losses, between $0.5 \mathrm{mg}$. and $1 \mathrm{mg}$. daily in adult men. During infancy and childhood, an additional amount will have to be absorbed to meet the requirements of growth, as the child's haemoglobin mass and iron content increase. The amount will be greatest during periods of rapid growth, but over the whole period of childhood, $0 \cdot 6$ $\mathrm{mg}$. of iron daily will be required. The total iron content of a normal diet in Great Britain is about $14 \mathrm{mg}$. per day (Davidson and Passmore, 1963). The intake of food iron in children receiving a normal diet will vary in proportion to the amount eaten, and in the case of the younger ones, may be substantially less than this. Healthy adult men do not become iron deficient or iron laden, and iron deficiency is not common in growing boys, or in girls in the years preceding the onset of menstruation. We may therefore conclude that enough iron to meet the normal losses and requirements of growth is absorbed from a diet containing quantities of iron up to $14 \mathrm{mg}$. Growing children might therefore be expected to absorb more iron than adult men, to 
TABLE 2

ABSORPTION OF FOOD IRON

\begin{tabular}{|c|c|c|c|c|c|c|c|c|c|}
\hline \multirow{2}{*}{\multicolumn{4}{|c|}{ Type of Food }} & \multirow{4}{*}{$\frac{\begin{array}{c}\text { Amount } \\
\text { of Iron } \\
\text { (mg.) }\end{array}}{5}$} & \multicolumn{4}{|c|}{ Mean \% Absorbed* } & \multirow{3}{*}{ Reference } \\
\hline & & & & & \multicolumn{2}{|c|}{ Normal } & \multicolumn{2}{|c|}{ Iron-deficient } & \\
\hline & & & & & Adults & Children & Adults & Children & \\
\hline Haemoglobin .. & $\cdots$ & $\cdots$ & $\cdots$ & & $12(25)$ & $22(8)$ & $25(27)$ & - & Bannerman et al. (1964), \\
\hline $\begin{array}{l}\text { Chicken liver } \ldots \\
\text { Chicken muscle }\end{array}$ & $\begin{array}{l}\cdots \\
\cdots\end{array}$ & $\begin{array}{l}\cdots \\
\cdots\end{array}$ & $\begin{array}{l}\cdots \\
\cdots\end{array}$ & $\begin{array}{c}6 \cdot 5 \\
9\end{array}$ & $\begin{array}{l}7 \cdot 7(5) \\
11(5)\end{array}$ & $8(3)$ & $3 \overline{3(2)}$ & 二 & $\begin{array}{l}\text { Moore and Dubach (1951) } \\
\text { Moore and Dubach (1951) }\end{array}$ \\
\hline Egg $\quad \ldots$ & $\cdots$ & . & $\cdots$ & $\begin{array}{c}6 \\
3 \cdot 5 \\
1 \cdot 2\end{array}$ & $\begin{array}{c}1 \cdot 4(14) \\
3 \cdot 8(8) \\
-\end{array}$ & $\overline{8} \overline{6(52)}$ & $3 \cdot \overline{8(5)}$ & Z & $\begin{array}{l}\text { Chodos et al. (1957) } \\
\text { Moore and Dubach (1951) } \\
\text { Schulz and Smith (1958a) }\end{array}$ \\
\hline Egg and milk .. & . & . & $\cdots$ & $1 \cdot 2$ & 一 & $5 \cdot 8(5)$ & 一 & $17(6)$ & Schulz and Smith (1958a) \\
\hline Milk .. & .. & $\cdots$ & $\cdots$ & $\begin{array}{l}0 \cdot 3 \\
0 \cdot 1\end{array}$ & $2 \cdot 8(6)$ & $9 \cdot \overline{5(14)}$ & - & $\overline{16(4)}$ & $\begin{array}{l}\text { Schulz and Smith (1958a) } \\
\text { Schulz and Smith (1958a) }\end{array}$ \\
\hline \multicolumn{4}{|c|}{ Vegetables (Swiss chard, beet greens) } & 3 & $1 \cdot 1(6)$ & 一 & - & - & Chodos et al. (1957) \\
\hline $\begin{array}{l}\text { Fortified cereals } \\
\text { Enriched bread }\end{array}$ & $\cdots$ & $\ddot{*}$ & $\ddot{\cdots}$ & $\begin{array}{l}3 \\
3\end{array}$ & $5 \overline{(28)}$ & $12 \cdot \underline{3(16)}$ & $5 \overline{5(3)}$ & - & $\begin{array}{l}\text { Schulz and Smith (1958a) } \\
\text { Steinkamp et al. (1955) }\end{array}$ \\
\hline
\end{tabular}

* Number of observations indicated by figures in parentheses.

meet the additional requirements of growth, though their iron intake may be slightly less. Studies of absorption of food iron, particularly in children, are not numerous (Table 2). Schulz and Smith (1958a) found a mean absorption of $10 \cdot 6 \%$ of a dose of $0 \cdot 1$ $\mathrm{mg}$. of iron in $6 \mathrm{oz}$. of milk, whereas adult men absorbed only $2 \cdot 8 \%$ of a comparable intake. An average of $8 \%$ of chicken liver iron was absorbed, and $8 \cdot 6 \%$ of egg iron. It was further demonstrated that children under 3 years of age absorbed egg iron about twice as well as the older ones. In similar studies with adults, Moore and Dubach (1956) found absorption of $3.8 \%$ of egg iron. Schulz and Smith also found a mean absorption of $12 \cdot 3 \%$ of iron in enriched cereals. The portions served were $6 \mathrm{~g}$., with $2 \mathrm{oz}$. of milk, containing a total of $3 \mathrm{mg}$. of iron. Bannerman, Callender, Hardisty, and Smith (1964) found that children absorbed a dose of $5 \mathrm{mg}$. of iron as haemoglobin approximately twice as well as adults. The mean values for iron absorption found in this study were $22 \%$ for the children, and $12 \%$ for the adults. Comparison of the absorption of various kinds of food iron in children shows that haemoglobin iron was absorbed to the greatest extent, even though the amount of iron was larger. Studies of absorption of food iron in adults (Chodos, Ross, Apt, Pollycove, and Halkett, 1957; Moore and Dubach, 1956) have also shown that there is a wide variation in absorption of iron in different kinds of food. These studies suggest that the iron in muscle meats is absorbed about four times as well as egg iron, and about 10 times as well as vegetable iron. Children may, therefore, derive a very substantial proportion of their food iron from meat, rather than from milk, eggs, or vegetables. Enriched cereal products represent a further valuable source of iron when these are given: although iron in this form may be slightly less readily absorbed than meat iron, the amount of iron in the portions normally served is many times greater than the iron in milk or vegetables. We may conclude that children normally absorb between 10 and $20 \%$ of the iron in meat, eggs, enriched cereal products, and milk. This corresponds to between 1 and $2.5 \mathrm{mg}$. of iron, if the diet is normal, and agrees well with the theoretical requirement based on normal losses and the requirements of growth.

Studies of iron absorption in infancy are limited to a small number of observations with ${ }^{59} \mathrm{Fe}$-labelled milk. Garby and Sjölin (1959) showed that newborn infants below the age of 1 month absorbed a mean of $72 \%$ of radioiron in milk, decreasing to $30 \%$ at 3 months of age. In similar studies with premature infants, Gorten, Hepner, and Workman (1963) found a mean absorption of $31 \cdot 5 \%$, and noted that the highest iron absorption values were obtained in the most rapidly growing infants. It is interesting to consider the question of iron deficiency and anaemia in early infancy in the light of these observations. Although growing infants may absorb iron well, a normal infant may treble his birth weight in the first year of life; the increase will be even greater in premature infants. Little stored iron is present at birth, probably not more than 10 to $25 \mathrm{mg}$. (McCance and Widdowson, 1951), but the high haemoglobin level in the normal infant at birth provides a source of some iron, the destruction of the excess red cells providing enough for the increase in the infant's size during the first two to four months of life. Studies with radioactive iron (Smith, Caton, Roby, Reid, 
Caswell, and Gibson, 1950) have confirmed that little, if any, exogenous absorbed iron is used in haemoglobin formation during this period, and if anaemia develops it is the result of decreased erythropoiesis rather than iron deficiency (Gairdner, Marks, and Roscoe, 1952; Seip, 1955; Garby, Sjölin, and Vuille, 1963). Thereafter, the rate of growth is so rapid that the iron requirement exceeds the amount which can be absorbed from the available diet, even though the iron may be well absorbed. The iron content of infant foods varies widely, and though some infants receiving heavily iron-enriched formulas may ingest 5 to $10 \mathrm{mg}$. of iron per day in food, those fed on milk alone may receive as little as $0.14 \mathrm{mg}$. per day (Sturgeon, 1956). By calculation from the birth weight and haemoglobin level, the anticipated increase in haemoglobin mass in a normal infant will require the absorption of about $2 \mathrm{mg}$. iron daily from the fourth month of life onwards. It is obvious that this cannot be achieved by the use of milk feeding without iron supplements, and irondeficiency anaemia may be expected to follow. It is also generally conceded that the early institution of mixed feeding will not lead to higher haemoglobin levels in either full-term or premature infants. Brokaw, Sedam, and Cassirer (1942) could demonstrate no difference in haemoglobin levels in normal infants fed solids early, as compared with those kept on milk during the first 12 months of life. This is perhaps not surprising, as the quantity of iron in such foods is relatively small in relation to the infant's requirements.

The deficiency of iron in many infant foods, including normal human breast milk, has led paediatricians to accept, as normal, levels of haemoglobin in infancy, which are considerably lower than those found in older children and adults. Sturgeon (1956) showed that this physiological anaemia of late infancy might be prevented by the parenteral administration of iron. 30 infants within the ages of 8 to 10 months were each given a total of $250 \mathrm{mg}$. of iron as iron dextran, and after 3 months they were found to have significantly higher haemoglobin levels than the untreated controls. Premature infants, whose iron requirement is even greater due to the initial greater iron deficit coupled with a more rapid rate of growth, almost invariably become anaemic, and this may be prevented by the administration of parenteral iron as iron dextran (Gaisford and Jennison, 1955; Elliott, 1962).

There is now good evidence that the prophylactic administration of oral iron, or the use of ironenriched cereals in infant feeding, will lead to higher haemoglobin levels and prevent much of the irondeficiency anaemia seen in otherwise normal infants.
Niccum, Jackson, and Stearns (1953) and Sturgeon (1958) showed that supplementation with oral medicinal iron will prevent iron-deficiency anaemia and lead to a higher mean haemoglobin level during infancy. Farquhar (1963), in a double blind controlled study of 44 infants, found higher levels of haemoglobin at 3,6,9, and 12 months in the experimental group who were given $5 \mathrm{mg}$. of iron as ferric pyrophosphate daily from the age of 1 month. A most noteworthy recent contribution in this field has been the work of Moe in Norway (1963). The effect of diets of varying iron content was studied in 255 normal healthy babies, who were divided into four groups, and given varying dietary iron intakes from the age of 3 months onwards. One group received no supplements, the remainder were fed cereals with an iron content of $5 \mathrm{mg}$. $/ 100 \mathrm{~g}$., $12.5 \mathrm{mg}$. $/ 100 \mathrm{~g}$., or $20 \mathrm{mg} . / 100 \mathrm{~g}$. The last group also received $15 \mathrm{mg}$. medicinal iron daily $(0.6 \mathrm{ml}$. Fer-In-Sol) to ensure a high iron intake. The two groups receiving the highest iron intakes had significantly higher haemoglobin levels at 1 year of age than the group receiving cereals containing $5 \mathrm{mg}$. iron/100 g., or the unsupplemented diet. Dietary histories were kept, and it was found that the actual iron intakes of the two groups with the highest supplements were over $20 \mathrm{mg}$., and $8 \cdot 6-13 \cdot 5 \mathrm{mg}$. It was concluded that an iron content of $12.5 \mathrm{mg} . / 100 \mathrm{~g}$. of cereal will assure an adequate iron supply for the normal infant, when cereals are fed regularly twice a day from the age of $3 \frac{1}{2}$ months. In an extension of the study (Moe, 1964) in which these infants were followed up to the age of 3 years, it was found that the infants in the two groups which had received cereals with the highest iron content maintained normal haemoglobin levels, and showed a negligible incidence of iron-deficiency anaemia. On the other hand, iron-deficiency developed in nearly one-third of the children receiving diets without iron supplements.

It is evident that the iron content of many infant diets is insufficient to meet the needs of growth. A high incidence of iron-deficiency anaemia can be prevented by supplements of oral iron which can be given conveniently and cheaply by feeding ironfortified cereals. A daily iron intake of $10-12 \mathrm{mg}$. by the end of the first year seems to be necessary. It is also possible that the lower levels of haemoglobin found in apparently normal infants fed without iron supplements may indicate some degree of latent iron deficiency. Mackay (1931) demonstrated a decrease in resistance to infections in infants with irondeficiency anaemia; iron medication was followed by a marked reduction in morbidity. It would be of great importance, in view of current interest in the effects of tissue iron deficiency without anaemia, to 
know whether the small increase in haemoglobin achieved by feeding iron-enriched cereals was accompanied by any improvement in rate of growth, and any decrease in the instance of infections. It still remains to be shown whether the premature infant requires medicinal iron to avoid the anaemia which is almost invariably seen in late infancy, or whether this could be prevented by the provision of a diet with a sufficiently high iron content. This problem deserves further study, as suitable ironenriched formulas and cereals could easily be prepared, and it is known that these infants absorb iron salts well.

\section{Iron Deficiency}

Aetiology. Iron deficiency occurs when the body's need for iron to meet the requirements of growth or to replace normal or pathological losses of iron is not met by alimentary absorption. This may be due to nutritional insufficiency, intestinal malabsorption of iron, or blood loss, which is the only way in which significant pathological amounts of iron can be lost from the body. More than one of these factors may contribute to the presence of iron deficiency in the individual patient.

Dietary insufficiency is probably the commonest cause of iron deficiency in infancy and childhood. It has already been shown that even in countries with a high standard of living, the usual types of infant foods contain an inadequate amount of iron, unless supplements are given; it is therefore not surprising that these infants have an incidence of iron-deficiency anaemia of $15-30 \%$. A much higher incidence of iron deficiency is found in areas inhabited by families of poorer economic means. Davis, Marten, and Sarkany (1960) found evidence of iron deficiency in $22.4 \%$ of white children in London, while the incidence in West-Indian immigrants was $53.5 \%$. The incidence of iron deficiency in children under the age of 3 years was stated to be approaching $30 \%$ in Cincinnati (Guest and Brown, 1957) and in Oslo (Moe, 1964). Among the poorer inhabitants of North East Scotland, $42 \%$ of infants under 2 years had a haemoglobin level more than $10 \%$ below the accepted normal (Davidson, Donaldson, Dyar, Lindsay, and McSorley, 1942). Incidences over $50 \%$ have been reported in Mauritius and in the Philippines (Stott, 1960; Stransky and Dauis-Lawas, 1948). Sturgeon (1954), using measurements of plasma iron and iron-binding capacity as an index of iron deficiency, found evidence of iron deficiency in approximately half of a group of infants from homes with good economic means. He suggested that a more rapid rate of growth in well-nourished children might account for the high incidence of iron deficiency.

In addition to inadequacy of the dietary supply of iron, a number of other factors modify the iron content of the newborn infant, and thus his subsequent iron requirement during infancy. In prematurity or twinning, the birth weight may be much lower than in normal single full-term births and the combination of the lower initial body iron content with a more rapid rate of growth leads to the development of iron deficiency in a very high proportion of such babies. The manner in which the cord is ligated will also influence the amount of iron present in the infant at birth. By draining the placenta through gravity, or by stripping the umbilical cord, the infant's blood volume may be increased by $20 \%$, with a consequent gain of about $50 \mathrm{mg}$. of iron by the infant. Simple delay in ligation of the cord has no such effect (Whipple, Sisson, and Lund, 1957). The infant's iron content does not seem to be adversely affected by maternal iron deficiency, unless it is very severe. Strauss (1933) found that anaemia during the first year was much more frequent in infants of mothers with a mean haemoglobin level of $5.3 \mathrm{~g} . / 100 \mathrm{ml}$. at term, and the studies of Sisson and Lund (1957) showed a significant reduction in red cell mass in the infants of anaemic mothers, compared with those born to women without significant anaemia. In contrast to this, Woodruff and Bridgeforth (1953) found no difference in haemoglobin levels up to 1 year of age in infants born to two groups of mothers, with mean haemoglobin levels of $9.9 \mathrm{~g} . / 100 \mathrm{ml}$. and $13.9 \mathrm{~g} . / 100 \mathrm{ml}$. at term. Furthermore Sturgeon (1959) showed that supplementation with oral iron or even the administration of large doses of parenteral iron to mothers during pregnancy did not influence the haemoglobin levels of their infants at 6,12 , or 18 months. It may be concluded that the infant's iron stores cannot be significantly increased, or the subsequent development of anaemia prevented, by the administration of iron to the mother during pregnancy, unless severe iron-deficiency anaemia is present.

Pathological blood loss is of considerable importance in the aetiology of iron-deficiency anaemia in infancy and childhood. Bleeding may be due to generalized bleeding disorders, such as haemophilia, familial telangiectasia, and idiopathic thrombocytopenic purpura. Frequent bleeding episodes in these and similar conditions often lead to irondeficiency anaemia which may be overlooked in the child's management. In the adolescent girl, heavy menstrual losses at the time of the menarche is a frequent cause of iron-deficiency anaemia, particu- 
larly as this occurs at a period of rapid growth.

Significant amounts of blood can be lost from the gastro-intestinal tract, without being noticed by the parents or physician. Such losses may be due to generalized bleeding disorders, or to local lesions such as Meckel's diverticulum, angioma, hiatus hernia, and in older children, regional enteritis and ulcerative colitis. On a global level, a major cause of iron-deficiency anaemia through bleeding is hookworm infestation. When iron-deficiency fails to respond to adequate treatment, or recurs rapidly, causes for occult gastro-intestinal bleeding should be sought.

Of particular interest is the very high incidence of occult blood loss in iron deficiency in infancy. Using radioactive iron, Hoag, Wallerstein, and Pollycove (1961) found significant blood loss in all of 13 infants studied. The amount of blood lost varied between $7 \mathrm{ml}$. and $107 \mathrm{ml}$. over a period of three to four weeks. Wilson, Heiner, and Lahey (1962) found occult blood in the stools of $41 \%$ of the infants studied, and many of these infants also had precipitins to cows' milk in their serum, and evidence of loss of significant quantities of serum proteins into the gastric juice. Whatever the primary cause, it appears that iron-deficiency anaemia may frequently occur in infancy from gastro-intestinal bleeding in the absence of anatomical lesions.

Malabsorption of iron is probably the least important cause of iron deficiency. This is not surprising, since the duodenum, which is the site at which iron is best absorbed, is rarely involved in pathological processes. The most important condition associated with the malabsorption of iron is idiopathic steatorrhoea, and coeliac disease in childhood. The block in iron absorption has been clearly demonstrated in studies using radioactive iron, and it can be shown that iron absorption returns to normal after treatment (Badenoch and Callender, 1954, 1960). Iron deficiency and malabsorption of iron have also recently been shown to be present in children with cystic fibrosis, possibly a consequence of prolonged treatment with pancreatin (Smith, 1964a). When iron deficiency cannot be corrected by oral iron in adequate doses, and careful search has failed to reveal any evidence of blood loss, malabsorption of iron may be suspected: this may prove to be part of a more generalized but unrecognized malabsorption syndrome (Whitehead, Carter, and Sharp, 1965). Malabsorption can be documented with certainty by means of radioactive iron absorption tests; a much less time-consuming procedure is the 'iron tolerance test' (Verloop,
Meeuwissen, and Blokhuis, 1958). Serial measurements of serum iron are made after a loading test dose of iron. If iron absorption is unimpaired, a single serum iron measurement, 30 minutes or one hour after the test dose, may be sufficient to exclude malabsorption as the cause of the iron deficiency.

Tissue Iron Deficiency. It has been well known for many years that many of the tissue changes seen in iron-deficiency anaemia are not found in other types of anaemia of equal severity. These changes include alterations in the epithelium of the mouth and alimentary tract, which may also be seen in patients without significant anaemia, but with evidence of reduced iron stores. The severity of the symptoms in patients with iron-deficiency anaemia is frequently unrelated to the haemoglobin level, and iron treatment may be followed by marked improvement in symptoms, which precedes the eventual haemoglobin rise. Beutler (1964) reviews the evidence that the tissues may be deprived of essential iron in the absence of anaemia. In experimental animals, it was shown that a number of enzymes, particularly aconitase and cytochrome $\mathrm{C}$, become very depleted in the earliest phases of iron deficiency, when haemoglobin levels are only slightly reduced. Although it has not yet been possible to relate any specific enzyme depletion in man with the symptomatology of iron deficiency, it is clear that the oldfashioned concept that enzyme iron is inviolate is not true. Anaemia may not always be the first symptom of iron deficiency, and at the present time the extent of morbidity from tissue deprivation of iron is unknown. Beutler, Larsh, and Gurney (1960) suggest that iron therapy may be of value in patients with chronic fatigue and malaise, normal haemoglobin levels, but reduced marrow iron stores.

These findings are of great interest to the paediatrician. Although we know that iron deficiency is very common in infancy and childhood, and that haemoglobin and serum iron levels are lower in infancy than in later childhood and adult life, we have no information on the extent of tissue iron deprivation in infancy and childhood, nor of its consequences. It would be of great importance to know whether the supplementation of infant foods with iron in sufficient quantities to raise the haemoglobin and serum iron levels will be accompanied by an increase in the rate of growth, or a reduction in morbidity from infections.

The Diagnosis of Iron Deficiency. Anaemia is the finding that most frequently alerts the paediatrician to the presence of iron deficiency, and the diagnosis normally rests on the demonstration of the presence 
of anaemia, and on the proof that iron deficiency is the factor limiting erythropoiesis. In most instances, a correct diagnosis can be made from the haemoglobin level, and examination of a stained peripheral blood smear, in which varying degrees of microcytosis, anisocytosis, poikilocytosis, and hypochromia are seen. In mild or early cases, estimation of the mean corpuscular volume (MCV), mean corpuscular haemoglobin $(\mathrm{MCH})$, and mean corpuscular haemoglobin concentration (MCHC) may be helpful. Of these, the MCHC is the simplest, as it can be calculated from the haemoglobin level and the haematocrit, and a red cell count is not required. Normal values in childhood are approximately $32-36 \%$, and in iron deficiency values below $30 \%$ are usually seen (Wintrobe 1961, pp. 105, 745).

There are several additional tests that may be of value in the demonstration of iron deficiency with minimal or insignificant changes in the peripheral blood, and in the differential diagnosis of hypochromic anaemia due to causes other than iron deficiency.

Plasma iron and iron-binding capacity. These measurements provide a very good index of the adequacy with which iron is being supplied to the marrow. In iron deficiency, plasma iron levels are low, and transferrin levels, measured by the total iron-binding capacity of the plasma, are raised. The ratio of the plasma iron to the total iron-binding capacity is expressed as the percentage saturation of the iron-binding capacity or transferrin. In iron deficiency, there is usually less than $20 \%$ saturation of the plasma transferrin, compared with $30-40 \%$ in normal subjects (Beutler, Robson, and Buttenwieser, 1958, Verloop et al., 1958). On the other hand, normal or raised levels of plasma iron, with normal or reduced levels of transferrin, and high levels of transferrin saturation are characteristically found in the hypochromic anaemias due to disorders of haemoglobin synthesis in the presence of an adequate iron supply, such as thalassaemia and the sideroachrestic and pyridoxine-responsive anaemias.

Marrow haemosiderin. Assessment of the quantity of haemosiderin in bone-marrow reticuloendothelial cells is the most useful method to determine the adequacy of the body's iron stores. It is generally agreed that the absence of haemosiderin indicates iron depletion, whereas if haemosiderin is present, the anaemia is almost certainly not due to iron deficiency, and iron therapy will be useless or even harmful. Beutler et al. (1958) found that assessment of the marrow haemosiderin provided a better indication of the adequacy of the body iron stores than plasma iron or transferrin saturation. It may, therefore, be a useful test when iron deficiency is suspected in spite of normal levels of plasma iron and transferrin. It is also helpful in differentiating between iron deficiency and anaemia due to infection, where increased quantities of marrow haemosiderin may be found in association with reduced saturation of the plasma transferrin. In such patients iron therapy is of no value.

Marrow sideroblasts and siderocytes. When the marrow normoblasts and reticulocytes are stained for iron, one or more aggregates of ferritin may be seen as small particles. In iron deficiency, these siderotic granules are absent, and in conditions such as thalassaemia, where hypochromic red cells are the result of a block in haem synthesis, siderotic granules are present in increased numbers. From a practical point of view, enough material for examination can frequently be obtained from the buffy coat of the peripheral blood, particularly in anaemia associated with a hyperplastic bone-marrow (Bothwell and Finch, 1962, p. 331).

Determinations of plasma iron and iron-binding capacity, marrow haemosiderin, and sideroblast and siderocyte iron, may be of help in documenting the presence of iron deficiency when blood counts are within normal limits, or when anaemia is due to infection rather than iron deficiency. They will also lead the clinician to suspect the correct diagnosis when hypochromic anaemia is due to a block in haem synthesis rather than to iron deficiency. The possibility of thalassaemia should always be considered when hypochromic anaemia fails to respond to iron treatment. This disease is seen increasingly in England, and in addition to cases arising in immigrants of Mediterranean origin, examples of homozygous and heterozygous thalassaemia have now been described in subjects of Anglo-Saxon stock (Lloyd and Brown, 1964). When the disease is suspected on clinical grounds, a diagnosis may be made by the demonstration of a marked increase in alkali-resistant haemoglobin.

There are a number of other rare causes of refractory hypochromic anaemia, all of which can be distinguished from iron deficiency on the basis of these tests. Of these the least uncommon are the sideroachrestic anaemias, which include the pyridoxine-responsive anaemias. These anaemias also seem to be due to a block in haemoglobin synthesis in the presence of adequate or excess iron (Bourne, Elves, and Israëls, 1965; MacGibbon and Mollin, 1965). Very rarely, hypochromic anaemia may be due to a defect in iron transport to the developing erythroblasts. A case of congenital absence of 
plasma transferrin has been described (Heilmeyer, Keller, Vivell, Keiderling, Betke, Wöhler, and Schultze, 1961); in another study, there was evidence of impaired transport of iron to the marrow in the presence of normal transferrin levels (Shahidi, Nathan, and Diamond, 1964).

\section{The Treatment of Iron-deficiency Anaemia}

The basis of iron therapy is to supply optimal amounts of iron to the marrow while avoiding toxic reactions. A wide variety of suitable oral and parenteral preparations are available for this purpose. When the degree of anaemia is life-threatening, transfusion may be needed, usually when iron deficiency is complicated by continuing blood loss which exceeds the regenerative capacity of the marrow. Transfusion is not often required in iron deficiency when active bleeding is not present, as the regenerative capacity of the marrow in infancy and childhood is very great. In these patients oral or parenteral iron is frequently followed by a rapid increase in haemoglobin level.

Oral Iron Therapy. In trying to formulate a rational basis for the use of oral iron, it is of interest to consider the maximum amount of iron which the marrow can handle in a state of blood regeneration from the stimulus of anaemia. Experiments using phlebotomy or ferrokinetics, and observations of the rate of response in patients under treatment, suggest that the optimal iron requirement varies between $0.3 \mathrm{mg}$. and $0.8 \mathrm{mg}$. per $\mathrm{kg}$. body weight daily (Finch, Haskins, and Finch, 1950; Coleman, Stevens, Dodge, and Finch, 1953; Giblett, Coleman, Pirzio-Biroli, Donohue, Motulsky, and Finch, 1956). Sufficient iron must be given to ensure that at least these quantities are absorbed. Iron salts have been shown to be well absorbed in iron deficiency (Bothwell et al., 1958; Callender, 1964), but allowance must be made for wide individual variations. Thus Callender (1964) found that 19 adults with iron deficiency absorbed between 14 and $94 \%$ of a dose of $5 \mathrm{mg}$. of iron as ferrous sulphate, and Riley (1960) obtained levels of absorption of between 10 and $92 \%$ of a dose of $30 \mathrm{mg}$. of iron as ferrous sulphate in anaemic infants. Schulz and Smith (1958b) found an average of $12-15 \%$ absorption of $30 \mathrm{mg}$. ferrous iron in children. These figures suggest that dosage up to $5 \mathrm{mg}$. $/ \mathrm{kg}$. daily may be needed to achieve an optimal erythropoietic response. As absorption of iron salts decreases in proportion to increasing dosage, and is to some extent reduced by the presence of food, it seems logical to divide the dose and administer it between meals.

The number of available oral iron preparations is perplexing. There is no doubt that ferrous salts are better absorbed than ferric salts, and it seems that ferrous sulphate is probably absorbed as well as any other. Studies have shown that the sulphate is absorbed as well as other ferrous salts, such as the succinate, gluconate, fumarate, lactate, citrate, and others (Brise and Hallberg, 1962). As ferrous sulphate is the cheapest, and apparently absorbed as well as any other, it seems to be the drug of choice, provided that it is well tolerated by the patient. Much has been written on iron intolerance, and it appears that the incidence is probably overestimated, and that psychological factors may enter into tolerance to a great extent (Girdwood, 1952; Kerr and Davidson, 1958). Children usually tolerate oral iron preparations well, unless excessive doses are given. In the event of intolerance to the sulphate a wide range of alternative tablets are available. For those unable to swallow tablets, either ferric ammonium citrate mixture BPC, or the least expensive of the proprietary preparations, such as 'Feravol Syrup', 'Fersamel Syrup', and 'Sytron elixir', (Brit. med. J., 1963), should be tried.

A great variety of more complex iron preparations are available, many of which claim advantages without foundation in fact, such as increased availability of iron, decreased toxicity, or the presence of additives which are supposed to assist the patient's response to iron therapy. At the present time, there is very little published evidence to indicate that any iron compound is superior to ferrous sulphate or similar salts. Although ascorbic acid can cause an increase in iron absorption (Brise and Hallberg, 1962), ferrous salts are absorbed so well alone, that the possible advantage of the additional ascorbic acid is probably hardly worth the expense. There are also a number of iron complexes, for which advantages are claimed, which are definitely less well absorbed than ferrous salts. These include certain carbohydrate-bound complexes, and iron versenate (Brise and Hallberg, 1962). The use of iron compounds containing other socalled haematinics is to be condemned. Recovery in iron-deficiency anaemia is not assisted by vitamin supplements or minerals (Moore, Minnich, Vilter, and Spies, 1943), and if other specific deficiencies are present it is important to identify them rather than to obscure their presence by multiple therapy.

Oral iron therapy in adequate doses may be expected to show rapid results, with reticulocytosis within three days, and a haemoglobin response up to $0.3 \mathrm{~g} . / 100 \mathrm{ml}$. per day when the initial haematocrit 
is below $20 \%$. Response is usually less when the initial haematocrit is higher. When the haemoglobin level has been restored to normal, iron therapy should be continued, probably for at least two to three months, in an attempt to replenish the stores.

Parenteral Iron Therapy. Although most cases of iron deficiency will respond to oral iron, and can be treated satisfactorily in this way, the availability of parenteral iron therapy is of great value when oral therapy is ineffective or unsuitable for any reason. It is specifically recommended when there is evidence of malabsorption of iron, and the anaemia cannot be corrected by oral therapy, or when the patient is completely unable to tolerate any kind of oral iron. It may also be necessary when there is chronic blood loss, and it proves impossible to correct the anaemia and replenish the stores by oral iron alone. A further indication may be in severely anaemic children, in whom prolonged oral therapy is needed, and the parents cannot be relied upon to follow the instructions.

If parenteral iron therapy is required, there are a number of available preparations: saccharated iron oxide and iron-dextrin are probably less suitable for use in children, as they must be given intravenously, and a number of excellent preparations are available for intramuscular use. Of these, iron-dextran (Imferon) and iron citric acid sorbitol complex (iron-sorbitol, Jectofer) are most frequently used at the present time. Both tend to cause a little aching after injection, but differ somewhat in the way in which they are handled by the body. Studies with ${ }^{59} \mathrm{Fe}$-labelled iron-dextran have shown that though the majority of the injected dose is rapidly used in haemoglobin synthesis, significant amounts remain at the site of injection, and are little mobilized for periods up to 100 days (Grimes and Hutt, 1957). The persistence of significant amounts at the site of injection may lead to skin staining, and it has been postulated, on the basis of animal experiments, that iron-dextran may be a local carcinogen (Richmond, 1959; Haddow and Horning, 1960). It must be stressed, however, that these results were obtained with massive doses, and there is no available evidence at the present time that the doses used in man are carcinogenic. There seems to be no good reason why the compound should not be given, if there are clear-cut indications for parenteral iron therapy.

Iron-sorbitol has overcome some of the drawbacks in the use of iron-dextran, and studies with ${ }^{59} \mathrm{Fe}-$ labelled material (Pringle, Goldberg, Macdonald, and Johnston, 1962; Wetherley-Mein, Buchanan, Glass, and Pearce, 1962) have shown that it is also well utilized in haemoglobin synthesis and is almost completely removed from the injection site in 24 hours. As a result, skin staining is seen less frequently than with iron-dextran, and so far no carcinogenic effect has been found, even using high doses in animals (Fielding, 1962). However, it suffers from the disadvantage that about $30 \%$ of the dose is excreted in the urine which turns black on standing (Boyle, Dellipiani, Owen, Seaton, and Tonkin, 1964), due to the formation of iron sulphide. This may be disconcerting to the patient, but more serious is the apparent ability of the iron to exacerbate pyelonephritis as it passes through the kidney (Scott, 1963; Briggs, Kennedy, and Goldberg, 1963). It therefore seems unwise to use this preparation in patients with urinary tract infection. Side-effects such as headache, dizziness, nausea, and vomiting have also been observed, possibly due to the concomitant administration of oral iron preparations (Scott, 1963). It seems advisable to discontinue oral iron therapy before starting treatment with any kind of parenteral iron. It appears that ironsorbitol and iron-dextran are both suitable for parenteral iron therapy in children. Another suitable compound may be iron polyisomaltosate (Mereu and Tonz, 1962). As a practical choice, many physicians may prefer to use iron-sorbitol, except in the presence of renal infection, until more information is available on the possible though remote risk that iron-dextran may be a local carcinogell.

These preparations all suffer from the disadvantage that repeated injections are needed. An interesting recent development is the administration of the total requirement of iron in a single intravenous dose (Marchasin and Wallerstein, 1964). In Great Britain there are a number of reports of the administration of $25-35 \mathrm{ml}$. of iron-dextran by slow intravenous infusion in $500-1,000 \mathrm{ml}$. $5 \%$ glucose or normal saline in pregnant women with severe irondeficiency anaemia (Basu, 1963; Powell, 1963). Although serious reactions to this form of treatment were noted in one study (Clay, Rosenberg, Sampson, and Samuels, 1965), this has not been the experience in a number of other centres, where total-doseinfusions of iron-dextran have been given safely (Goldthorp, Spencer, and Dawson, 1965). Further experience is needed, but if this form of therapy is found to be free from serious side-effects, total-doseinfusion of iron might be a welcome alternative to long courses of intramuscular injections in severely anaemic children.

\section{Toxic Effects of Excess Iron}

It is well known that an excess of iron in the 
tissues is toxic. Acute poisoning with iron salts is common in infancy, and if enough is ingested may lead to death within a short period. The toxic effects of chronic iron deposition in the tissues have been recognized for many years in idiopathic haemochromatosis, and more recently in transfusion haemosiderosis. Iron overload is seen more frequently in children, now that improved medical care and blood transfusions have prolonged survival in conditions such as thalassaemia, and the hypoplastic and aplastic anaemias.

Iron-chelating Agents. Until recently there was no specific therapy for acute iron poisoning, or chronic iron overload. However, the advent of repeated venesection therapy for haemochromatosis showed that large quantities or iron could be mobilized, even after many years' storage in the tissues. This finding suggested that chelating agents might be used as an alternative method to bind and remove excess iron. Suitable chelating agents might be expected to render harmless unabsorbed iron in the gut and excess circulating iron in the blood and tissues in acute iron poisoning, and mobilize excess stored iron in conditions of chronic iron overload. However, the use of iron-chelating agents raises many problems. Iron, unlike toxic substances such as lead which are present in relatively small amounts, is a physiological substance; the quantities that cause toxicity, and which therefore must be bound and removed to achieve a useful therapeutic effect, are massive. Suitable chelating agents must therefore be nontoxic even when given in very large doses; they must have a high affinity for iron, yet their affinity for essential substances such as calcium and magnesium must be low enough to prevent significant depletion of these substances during therapy. On the other hand, the chelating agent should not interfere with the normal process of iron metabolism by removal of iron from haemoglobin or essential enzymes, or inhibit haemoglobin synthesis by removal of essential iron from the plasma transferrin or developing erythroblasts.

Some iron can be mobilized and removed by the use of ethylenediaminetetra-acetic acid (EDTA) or British-anti-Lewisite (Ohlsson, Kullendorff, and Ljungberg, 1953; Seven, Gottlieb, Israel, Reinhold, and Rubin, 1954). The limited quantities of iron removed, combined with possible side-effects of long-term administration, suggest that these substances are of little value in the treatment of chronic iron overload, although EDTA may be of therapeutic value in acute iron poisoning (Covey, 1964). In recent years three new chelating agents have been developed, which have been shown to be much more effective in the removal of iron from the body. Two of these are synthetic substances: ethylenediamine di-ortho-hydroxyphenyl acetic acid (EDDHA) (Korman, 1960), and trisodium calcium diethylenetriaminepenta-acetate (DTPA) (Fahey, Rath, Princiotto, Brick, and Rubin, 1961). Early experiences with these substances showed that up to $100 \mathrm{mg}$. of iron could be removed from patients with iron storage by a single infusion of either substance (Cleton, Noyes, Turnbull, and Finch, 1961; Fahey et al., 1961).

A different kind of iron-chelating agent was prepared by removing iron from the highly stable iron-chelate ferrioxamine which was isolated from Streptomyces pilosus. The iron-free substance, desferrioxamine, was found to have a very high affinity for iron but not for any other metals or the alkaline earths. One molecule of desferrioxamine combines with a single atom of trivalent iron: $9 \cdot 3 \mathrm{mg}$. of iron can theoretically combine with $100 \mathrm{mg}$. of desferrioxamine (Vischer, 1961). In vitro studies showed that desferrioxamine was capable of removing iron from haemosiderin and ferritin, the main iron storage complexes, and administration to iron-laden animals and patients was followed by mobilization and excretion of iron without any interference with erythropoiesis, or depletion of essential substances (Wöhler, 1961). After parenteral administration, it seems that desferrioxamine combines with stored iron, after which it circulates as ferrioxamine until removed by excretion through the kidney. This takes place rapidly during the first 6 hours after administration and is virtually complete in 24 hours (Nielsen, 1963).

Desferrioxamine, DTPA, and EDDHA, all have a much higher affinity for iron than the earlier chelating agents. There have been no further reports on the use of EDDHA, but desferrioxamine has now been successfully used in the treatment of iron poisoning, and both desferrioxamine and DTPA have given promising results in the management of chronic iron storage in adults and children.

Acute Iron Poisoning. Iron is one of the most important causes of accidental poisoning in Great Britain. This is probably because iron deficiency is common, and many oral iron preparations are presented as attractively coloured tablets, similar to some of the most popular brands of sweets. The clinical course is often severe, characterized by vomiting, gastro-intestinal bleeding, and peripheral vascular collapse, followed by severe shock, with cyanosis, lethargy, and restlessness. Vigorous supportive therapy may lead to improvement, but subsequent relapse several hours or one to two days 
later is not uncommon. The mortality rate approaches $50 \%$, and some of the children who recover face the prospect of scarring, leading to stricture of the stomach, and pyloric stenosis (Ross, 1953; Shepherd, 1955; Jacobziner and Raybin, 1962). The lower limit of the toxic dose of iron in children is not known, but severe symptoms were seen in a 2-year-old boy who ingested only eight $0 \cdot 3 \mathrm{~g}$. ferrous sulphate tablets (Jacobziner and Raybin, 1962), while death from late sequelae occurred in one child who may have ingested as few as six tablets (Ross, 1953). It therefore seems wise to institute appropriate therapy, unless it is known with absolute certainty that not more than two or three tablets have been ingested.

Immediate treatment. Attempts should be made to induce vomiting, and to delay any further absorption of iron by reducing its solubility. For this purpose, sodium bicarbonate, eggs, and milk may be helpful. Gastric lavage should be carried out as soon as possible, and the stomach irrigated with sodium bicarbonate solution. For this purpose a wide-bore tube should be used if possible, in order to aspirate any undissolved tablets.

Supportive measures. Shock needs urgent therapy, and the serum electrolytes, especially bicarbonate, should be determined. Alterations in acid-base balance should be corrected by intravenous fluids, and oxygen therapy may be needed.

Specific therapy: chelation of iron. This has a twofold aim: first, to prevent further absorption by binding any residual iron in the gastro-intestinal tract, and secondly, to chelate the excess iron in the plasma and tissues so that it is converted into a non-toxic form which can be excreted rapidly. Desferrioxamine was suggested for this purpose by Moeschlin and Schnider (1963) on the basis of animal studies. Henderson, Vietti, and Brown (1963) describe the treatment of a $14 \frac{1}{2}$-month-old infant who had ingested a large quantity of ferrous gluconate tablets. $5 \mathrm{~g}$. desferrioxamine were given through a naso-gastric tube, together with $800 \mathrm{mg}$. intravenously: further intravenous doses of $800 \mathrm{mg}$. were given 12 and 24 hours later. Clinical improvement was marked, and the serum iron, which had initially been $2,500 \mu \mathrm{g}$. per $100 \mathrm{ml}$., fell within 5 hours to a normal level; $25 \mathrm{mg}$. of iron were excreted in the urine. Desferrioxamine has also been used successfully in the treatment of iron poisoning by Powell and Dugdale (1964) and Whitten, Gibson, Good, and Goodwin (1964). In the latter study, 13 children who had ingested varying amounts of iron were treated, and all survived. However, hypotensive attacks were noted when some of the children were given intravenous desferrioxamine in doses up to $1.5 \mathrm{~g}$. in 15 minutes or less. This type of side-effect has not been seen after intramuscular injection, or when slow intravenous infusion is used.

Although the clinical reports are few so far, it seems that desferrioxamine has a valuable and possibly life-saving role in the management of iron poisoning. Treatment with desferrioxamine should be instituted without delay, using both the oral and parenteral routes. After gastric lavage, $5 \mathrm{~g}$. desferrioxamine should be introduced into the stomach. This can be dissolved in as little as $20 \mathrm{ml}$. of water, and is enough to bind over $400 \mathrm{mg}$. iron, or the amount contained in 10-12 ferrous sulphate tablets. The dose of oral desferrioxamine may possibly be increased if there is reason to believe that more than this amount remains in the stomach, but at present it is not known whether any adverse effect results from the administration of larger quantities by mouth. Desferrioxamine should also be given parenterally: rapid intravenous injections should be avoided and the drug administered intramuscularly, or by slow intravenous infusion, or by both methods in combination. It is known that desferrioxamine is rapidly absorbed after intramuscular injections, though the rate may be lower in children with severe peripheral circulatory collapse. Accordingly, 2 g. desferrioxamine should be given intramuscularly without delay, supplemented by intravenous administration of a further amount, which should not exceed $15 \mathrm{mg}$. $/ \mathrm{kg}$. hour, or a maximum of $80 \mathrm{mg}$. $/ \mathrm{kg}$. in 24 hours. In the event of relapse, additional intramuscular injections of $2 \mathrm{~g}$. desferrioxamine can be given at 12-hourly intervals. It is possible that these dosages will need modification in the light of experience and that it will prove perfectly safe to give much larger amounts of desferrioxamine by the intravenous route. Experience in the use of desferrioxamine in children with chronic iron overload (Smith, 1964b) has shown that much larger amounts can be given to small children without sideeffects, provided that they are infused slowly.

The reports of its successful use, and the fact that it is readily available in Great Britain, suggest that desferrioxamine (Desferal) is at the present time the specific chelating agent of choice in the treatment of acute iron poisoning. The drug should be available at general and children's hospitals and poison centres throughout the country, so that there is no delay in its use when indicated. As an alternative, EDTA or DTPA might be used if they are readily available in the absence of desferrioxamine. Other methods of removing iron from the body that have been tried in 
iron poisoning include peritoneal dialysis (Covey, 1964) and exchange transfusion (Amerman, Brescia, and Aftahi, 1958; Jacobziner and Raybin, 1962). Although some iron is removed by either of these methods, the amounts are much smaller than can be achieved by the use of desferrioxamine, which also has the important advantage that it forms a non-toxic chelate with the iron. It is doubtful whether these measures now have any place in the management of acute iron poisoning.

\section{Chronic Iron Overload.}

Repeated blood transfusion over many years leads to a progressive deposition of iron in children with thalassaemia, congenital pure red cell aplasia, and some hypoplastic, aplastic, and haemolytic anaemias. Many of these anaemic children also absorb iron through the intestinal tract in increased amounts. Although these children may tolerate the deposition of large quantities of iron for many years without ill effect, impairment of organ function is eventually seen, leading to death from cardiac or hepatic failure.

Pathogenesis. The quantity of iron accumulated through blood transfusion is more readily assessed than that absorbed from food. Although it is frequently stated that a bottle of blood contains $250 \mathrm{mg}$. iron, the haemoglobin level and amount transfused from a single bottle suggest that a more realistic figure is $200 \mathrm{mg}$. In a study of the amount transfused to 18 children with thalassaemia or pure red cell aplasia, varying between 3 and 15 years of age (Smith, 1964b), it was found that the daily iron gain from transfused red cells varied between $2 \cdot 2$ and $17.0 \mathrm{mg}$. per day, or 0.73 to $6 \cdot 2 \mathrm{~g}$. per year. Most of the children over 5 years were shown to be accumulating about 3 to $4 \mathrm{~g}$. or iron per year from transfusions. The massive quantity of iron accumulated is at once apparent: in comparison with a normal adult's iron stores of about $1 \mathrm{~g}$., many of these children, if transfused from early infancy, will accumulate between 50 and $200 \mathrm{~g}$. of iron from blood transfusions, by the time they reach adult life.

An additional quantity of iron will inevitably be absorbed through the intestinal tract from food. Although there are many studies suggesting that iron absorption is reduced in the presence of iron loading, these children always show some degree of anaemia, and many have hyperplastic bone-marrows, both of which factors might be expected to increase iron absorption. Several recent studies suggest that many iron-laden anaemic patients have increased absorption of iron. Robertson, Maxwell, and Elliott (1963) found increased absorption of small doses of ferric chloride in children with thalassaemia, all of whom had been repeatedly transfused and showed evidence of iron overload. Erlandson, Walden Stern, Hilgartner, Wehman, and Smith (1962) measured the absorption of a dose of $5 \mathrm{mg}$. of iron as ferrous sulphate in 19 anaemic children with thalassaemia or sickle-cell disease. A mean absorption of $45 \%$ was found, compared with $14 \%$ in the control group. On the other hand, when the absorption of $5 \mathrm{mg}$. of iron as haemoglobin was studied by Bannerman et al. (1964), it was found that most of the thalassaemic children absorbed less iron than the control group. Anaemic patients with hypoplastic bone-marrows may also absorb more iron than normal controls (Schiffer et al., 1965). It has been further demonstrated that the increased iron absorption found in these anaemic patients can be reduced to levels approaching normal when the patient's haemoglobin level is raised by transfusion; this has been demonstrated in anaemic patients with both hypoplastic and hyperplastic bone-marrows (Erlandson et al., 1962; Schiffer et al., 1965). The available evidence suggests that anaemia, whether associated with a hyperplastic or hypoplastic bone-marrow, is frequently associated with increased absorption of inorganic iron, even in the presence of iron loading. Absorption is reduced when the haemoglobin level is raised by transfusion, but even then some absorption of iron persists.

The absorption of haemoglobin iron on the other hand may be reduced in anaemic children with iron loading. It may be concluded that these children will accumulate significant amounts of iron from food over the years, though it is not possible to assess the amount of iron absorbed daily on the basis of these studies. The finding that it is inorganic iron that is absorbed most avidly by these children suggests that iron-enriched cereal foods may contribute more to their load than foods containing iron-porphyrin complexes, such as meat or liver. However, it is possible that $1 \mathrm{~g}$. of iron or more might be absorbed from food each year, particularly by the older children, fed a normal diet including the usual ironenriched foods.

It can be seen that many of these anaemic children accumulate iron from transfusions and alimentary absorption at a rate of $5 \mathrm{~g}$. or more yearly, of which the greater proportion is derived from transfusions. If fewer transfusions are given, the amount absorbed from food will increase. In assessing the net iron gain, allowance must be made for any loss of iron from the body. It is not known how much iron is excreted by these children: a single observation in an adult with transfusion haemosiderosis indicated a daily iron loss of $4 \mathrm{mg}$. (Crosby et al., 1963). This increased iron loss is probably mainly derived from the increased iron content of desquamated cells and 
secretions: children might be expected to lose less, in proportion to their size, and on this basis we may conjecture that they lose amounts up to $20 \mathrm{mg}$. $/ \mathrm{kg}$. year. If this is so, the rate of iron deposition will be reduced by less than $20 \%$ as a result of iron loss.

It is of interest to speculate why some of these children, who develop a load of over $50 \mathrm{~g}$. of iron, mostly from transfusions, show minimal evidence of impaired organ function. In contrast to this, patients with idiopathic haemochromatosis, where the iron load is derived from alimentary absorption, may show evidence of damage to the liver and pancreas, when the total amount of excess iron in the body is less than $20 \mathrm{~g}$. It has been suggested that iron derived from transfused red cells is less toxic to the tissues than iron absorbed from the intestine. It is certainly true that the initial handling is different: in conditions associated with iron storage, iron from transfused red cells is deposited in reticuloendothelial cells and may remain there for long periods, whereas iron absorbed through the intestinal mucosa gains immediate access into the plasma, and a high proportion finds its way into the parenchyma of organs such as the liver. This difference in handling is reflected in the pathological findings. In haemochromatosis, the deposition of iron is mostly parenchymal, and hepatic cirrhosis is present. A similar pattern of iron deposition with cirrhosis may be seen in thalassaemia (Witzleben and Wyatt, 1961; Fink, 1964). Intestinal absorption clearly makes a significant contribution to the deposition of iron in this disease, especially when transfusions are given only infrequently, and cases have been reported where more iron was found at necropsy than could be accounted for by transfusion (Ellis, Schulman, and Smith, 1954).

On the other hand, in patients who have received numerous transfusions, the deposition of iron is predominantly in the reticuloendothelial system, and cirrhosis is less frequently seen. Cappell, Hutchison, and Jowett (1957) showed extensive iron deposition, which was predominantly reticuloendothelial in distribution, but no cirrhosis, in a number of patients who had received multiple transfusions, including 2 patients in whom over $50 \mathrm{~g}$. of iron were found in the liver alone. Oliver (1959) found that cirrhosis was the accompaniment of iron deposition most frequently in patients with disorders associated with a hyperplastic bone-marrow, who might be expected to have parenchymal iron deposition from increased intestinal absorption. However, impaired organ function and cirrhosis were found in a number of patients with aplastic bone-marrows, who had received over $30 \mathrm{~g}$. of iron in transfusions.

It is difficult to escape the conclusion that even though red-cell iron may be deposited initially in the reticuloendothelial system, redistribution of iron with eventual parenchymal damage to vital organs must occur. The time taken by this process may well vary in different patients, and it is possible that marrow hyperplasia with an associated rapid plasma iron turnover may hasten parenchymal damage by speeding the redistribution of reticuloendothelial iron as well as enhancing intestinal absorption. If so, the child with erythroid aplasia should be able to tolerate the greatest iron load before the inevitable redistribution of iron and parenchymal organ damage is seen.

Therapy. Until recently, attempts to remove significant amounts of iron from the body have been unsuccessful, and the management of these patients has consisted in restricting the amount transfused to the lowest possible limit, in order to delay the ultimate inevitable onset of organ damage. Pancreatic involvement is not seen as frequently as in idiopathic haemochromatosis, and when diabetes occurs it can be treated with insulin. Cardiac and hepatic failure are more common, and usually lead to death within a few months (Witzleben and Wyatt, 1961 ; Engle, 1964).

Removal of stored iron by chelating agents. There is now a wealth of evidence showing that significant amounts of iron can be removed from patients with iron overload by the use of desferrioxamine or DTPA. Parenteral administration is essential: oral doses of desferrioxamine or DTPA produced no significant level of iron excretion in four heavily ironladen patients, all of whom showed marked iron excretion when the drugs were given parenterally Bannerman, Callender, and Williams, 1962; Smith, 1964b). The intravenous and intramuscular routes have been used successfully with both drugs.

Intravenous route. In the earliest studies with DTPA (Fahey et al., 1961), adults with iron-storage disease were given intravenous infusions of 2.4-4 g., after which up to $100 \mathrm{mg}$. of iron was excreted in the urine. Robertson et al. (1963) used infusions of 60-80 mg. DTPA $/ \mathrm{kg}$. body weight in thalassaemic children, which removed up to $33 \mathrm{mg}$. of iron. In most of the studies with intravenous desferrioxamine, lower doses have been used; in a large number of observations on the treatment of adults with haemochromatosis, and of adults and children with transfusion haemosiderosis, infusions of $0 \cdot 2-1 \cdot 2 \mathrm{~g}$. of desferrioxamine were used, with a maximum excretion of $40 \mathrm{mg}$. of iron (Wöhler, 1961, 1963; Smith, 1962). The effects of intravenous infusions of equal 
doses of desferrioxamine and DTPA were compared in iron-laden children with thalassaemia or pure red cell aplasia (Smith, 1964b); it was found that infusions of 1 or $2 \mathrm{~g}$. of desferrioxamine or DTPA were followed by comparable levels of iron excretion, with an average of $20-25 \mathrm{mg}$. of iron excreted per $\mathrm{g}$. of chelating agent administered. However, when doses of 3-6 g. were studied in three of the most heavily iron-laden children, it was found that in two of the three, the excretion of iron following desferrioxamine did not exceed the level achieved on a dose of $2 \mathrm{~g}$., while $100-230 \mathrm{mg}$. of iron were removed after doses of 4-6 g. DTPA. In this study, the chelating agents were given at the time of blood transfusion, the dose being divided and mixed in the blood or sedimented red cells: though doses up to $180 \mathrm{mg}$. $/ \mathrm{kg}$. of desferrioxamine or DTPA were given, the dose rate was never higher than $20 \mathrm{mg}$. $/ \mathrm{kg}$. hour. No toxic effects were observed with either drug when given in this way.

Intramuscular route. There are a number of studies in which patients have received intramuscular or subcutaneous injections of $0 \cdot 4-1 \cdot 2$ g. of desferrioxamine daily. In this dose range, the quantity of iron removed is about the same whether the intravenous or intramuscular route is used (Bannerman et al., 1962; Wöhler, 1963; Norman, 1964; Smith, 1964b). When given daily the average amount of iron excreted may be slightly less, but may reach an impressive total amount, over a period of weeks, months, or years. For example, Wöhler (1963) reported that a 4-year-old boy with congenital pure red cell aplasia excreted 12-14 mg. or iron daily during a 7-month period of treatment, which would amount to the removal of $4 \mathrm{~g}$. of iron from the body in a year. Moeschlin and Schnider (1963) treated an 8-year-old boy with thalassaemia with daily desferrioxamine injections for two months, and then with intermittent courses; in a little over 6 months, $675 \mathrm{mg}$. of iron were removed. Over a period of three months, iron excretion levels averaging $10 \mathrm{mg}$. a day were found in several heavy iron-laden children with redcell aplasia or thalassaemia, when treated by daily injections of $0.5 \mathrm{~g}$. desferrioxamine. If continued, this would amount to the removal of about $3.5 \mathrm{~g}$. of iron in one year (Smith, 1964b).

It seems possible that very large amounts of iron can be removed from some patients by prolonged desferrioxamine treatment over many months or possibly years. In the treatment of adults with haemochromatosis, using larger intramuscular doses, quantities of iron up to $18 \mathrm{~g}$. have been removed in little over a year (Heilmeyer and Wöhler, 1963). No toxic effects have yet been noted in patients following prolonged administration of desferrioxamine, and the injections are not painful, even when long courses are given.

DTPA can also be given by intramuscular injection, but has several important disadvantages. The injections are very painful (Robertson et al., 1963) unless mixed with procaine. Although DTPA was given on alternate days to one patient for a period of 17 days without ill effects (Fahey et al., 1961), longterm studies with this drug have not been made. Heilmeyer and Wöhler (1963) state that DTPA is too toxic for long-term use, and the studies of MullerEberhard, Erlandson, Ginn, and Smith (1963) showed that administration of DTPA to thalassaemic children was followed by a marked increase in the amount of magnesium in the urine, accompanied by a significant fall in the serum magnesium levels. It appears wise to limit the use of this drug to intermittent infusions.

Choice of drug and route of administration. It can be seen from these reports that it is possible to remove significant amounts of iron from the body by the use of either intravenous infusions or intramuscular injections of chelating agents. If treatment is to be effective, we must aim to remove from the body an amount of iron equalling or preferably exceeding the rate of accumulation; this amounts to $5 \mathrm{~g}$. a year or even more in many cases. Available reports suggest that on average not much more than $20 \mathrm{mg}$. of iron is removed by each $\mathrm{g}$. of chelating agent, irrespective of the route of administration, and this means that $250 \mathrm{~g}$. of chelating agent must be given to remove $5 \mathrm{~g}$. of iron. We must, therefore, select a plan of therapy that enables amounts of this order to be administered without causing toxicity, and with a minimum of discomfort to the child. 3-4 g. of iron a year can probably be removed from many of these children by a daily injection of $0.5 \mathrm{~g}$. of desferrioxamine. This amount can be dissolved in $2 \mathrm{ml}$. of water with the formation of an isotonic solution, which can be injected painlessly without any local side-effects by the subcutaneous route. It is possible that the rate of iron removal could be increased by using larger doses, or by giving two doses daily instead of one. Wöhler (1963) has reported the use of $1 \cdot 2 \mathrm{~g}$. desferrioxamine daily in an adult for over a year, and $0.6 \mathrm{~g}$. daily in a 4-year-old boy with red-cell aplasia.

As an alternative or supplement to prolonged courses of injections, intravenous infusion should be considered. A single infusion of desferrioxamine or DTPA may remove as much iron as 20 injections; unfortunately many of these children are the most difficult of subjects for repeated intravenous work, 
and furthermore slow infusions require hospitalization, at least for the day. Most of these children, however, receive periodic blood transfusions, and this procedure provides a useful opportunity for the administration of a large therapeutic dose of a chelating agent. For this purpose DTPA was found superior, and on some occasions infusions of 4 or $6 \mathrm{~g}$. of DTPA removed over $200 \mathrm{mg}$. of iron (Smith, 1964b). If iron can be removed regularly at this rate, 1-2 g. of iron can be removed each year by this means, depending on the frequency of transfusion. As transfusions are widely spaced in time, the possibility of magnesium depletion from the large dose of DTPA used seems to be remote. If this scheme of therapy is chosen, it seems wise to begin with to give alternate doses of desferrioxamine or DTPA at successive transfusions, increasing the dose progressively. On the basis of the figures of iron output obtained, a logical choice of drug and dose can be made.

It seems that intravenous and intramuscular therapy can be combined; it was found that desferrioxamine injections could be resumed, with continuing output of iron, only 48 hours after a large infusion of desferrioxamine or DTPA had been given, which had removed over $200 \mathrm{mg}$. of iron from the body (R. S. Smith, 1965, unpublished observations). One patient, a 14-year-old girl with thalassaemia, and another 14-year-old boy with pure red-cell aplasia, had been trained to dissolve the drug and give themselves their own injections at home.

Selection of patients for treatment. It has been found that significant levels of iron excretion following chelating agents are only achieved in patients with evidence of iron deposition. In practice, it seems that useful levels of iron output can usually only be achieved in children who have received repeated transfusions for 4 years or longer (Muller-Eberhard et al., 1963; Smith, 1964b). Infants with thalassaemia who had never been transfused excreted less than $2 \mathrm{mg}$. of iron after an infusion of $1 \mathrm{~g}$. of desferrioxamine or DTPA. It therefore seems unlikely that iron-loading can be prevented by the prophylactic administration of chelating agents. In selecting patients for treatment, the simplest practical measure is to administer a test dose, either intramuscularly or intravenously, and measure the iron output. This might be given by infusion when the child is receiving a blood transfusion, or as an intramuscular dose. As the iron chelate is mostly excreted in the first few hours after the dose (Nielsen, 1963), collection of urine for 6 hours is adequate. The quantity removed will indicate whether a worth-while output of iron will be achieved on continuous treatment. It may be useful to study the effect of a test dose of desferrioxamine at yearly intervals in children receiving regular blood transfusions, in order to ascertain the point at which useful therapy can be begun.

The collection of urine for 6 hours after an intramuscular injection of desferrioxamine is a simple and safe procedure that can be readily carried out on out-patients. In addition to the selection of patients for treatment with chelating agents, such a test may be of value in determining the presence of increased iron stores in children with refractory or haemolytic anaemia, or in the sons of men with haemochromatosis.

Results of therapy. The amount of iron removed can be determined from the iron content of the urine. For this purpose, wet-ashing is not necessary, and simple colorimetric methods can be used (Bannerman et al., 1962; Smith, 1962; CIBA, 1964). The patient and nurses should not be alarmed if the urine becomes red-brown after desferrioxamine, as this is due to the colour of ferrioxamine: the iron-chelate formed with DTPA is colourless. When children are receiving daily injections of desferrioxamine at home, 24-hour daily urine collections may be impracticable: in these patients the rate of iron removal can be estimated from one or more 24-hour collections at intervals, always beginning immediately after an injection.

In measuring iron excretion great care must be taken that all urinals, bedpans, and specimen bottles are iron free. The plastic bags and tubes used to collect urine from infants should be tested: in one study they were found to be free of iron (Smith, 1962).

It is not yet known to what extent these iron-laden children will benefit from the removal of iron. It is well known that many of the signs and symptoms of haemochromatosis improve after venesection: removal of iron by means of chelating agents might be expected to give similar results. During treatments there is often subjective improvement and reduction in pigmentation; improvements in plasma protein levels and liver function tests have also been noted. In one patient with thalassaemia, from whom $14 \mathrm{~g}$. of iron were removed by desferrioxamine therapy, liver biopsies before and after treatment showed that almost all the liver iron had been mobilized (Wöhler, 1963). Not infrequently these children show only minimal alterations in plasma proteins and liver function tests, even when there is massive iron loading, until abrupt deterioration occurs at termination (Witzleben and Wyatt, 1961). It may, therefore, only be possible to assess the therapeutic value of chelating agents in terms of prolonged survival and 
decreased morbidity resulting from long-term therapy. Serum iron levels may be expected to remain high until a large proportion of the excess stored iron has been removed. It is possible, however, that the removal of even small quantities of iron may be of benefit, even if the total amount of iron in the body is only slightly reduced. It is evident that many of these children can tolerate a very large excess of iron for prolonged periods: the improvements that have followed the removal of relatively small amounts of iron suggest that desferrioxamine may perferentially remove iron from areas where it exerts its most toxic effects.

An important additional benefit has been seen in patients with sideroachrestic anaemia, where removal of iron by desferrioxamine has been accompanied by an increase in the haemoglobin level, and a decrease in red-cell and urine porphyrins. It has been postulated that this is due to removal from the bonemarrow of the excess iron which blocks some of the enzymes involved in haem synthesis (Wöhler, 1963). Steiner, Baldini, and Damashek (1964) also found a decrease in marrow non-haem iron, and an increased activity of haem-synthesizing enzymes in a patient with thalassaemia, treated by desferrioxamine. The possibility may, therefore, exist that increased erythropoiesis and a decrease in transfusion requirements might result in thalassaemia, if enough iron could be removed.

Control of iron absorption and accumulation. The rate of iron accumulation would be significantly reduced if alimentary absorption could be prevented. Wöhler (1963) suggested that desferrioxamine should also be given routinely by mouth to block iron absorption in patients with iron overload, but recent studies cast doubts on the usefulness of this measure. Although desferrioxamine will block the absorption of inorganic iron, it does not reduce the absorption of iron incorporated in haemoglobin, or in chicken liver or meat (Bannerman and Malpas, 1965; Hwang and Brown, 1965). Furthermore, although it has been shown that desferrioxamine will block the absorption of a test dose of inorganic iron, studies have not yet been made of its effect on the absorption of the inorganic iron in a meal. It is possible that the effect of desferrioxamine in this situation might be influenced by the bulk of the meal, or by the presence of other substances in food. As the absorption of tightly-complexed organic food iron is not influenced by desferrioxamine, and its effect on the absorption of the inorganic part of food iron is not yet known, it seems unjustified at the present time to administer large doses of this expensive drug by mouth for this purpose.
It is also possible that the absorption of food iron might be reduced by the use of pancreatic extracts. It has been shown that the absorption of both inorganic iron and iron-porphyrin is reduced in the presence of pancreatin (Biggs and Davis, 1963; Callender and Malpas, 1963). It is not yet known whether this effect of pancreatin is due to a single enzyme: if so, the appropriate factor might be given in concentrated form as an alternative to the rather bulky preparations of whole pancreas.

Attention might profitably be directed to ways in which the iron intake might be reduced by restriction of the dietary iron content. Comparison of the available data suggests that thalassaemic children absorb inorganic iron to a much greater extent than porphyrin-iron (Erlandson et al., 1962; Robertson et al., 1963; Bannerman et al., 1964). It therefore seems possible that the inorganic part of food iron may contribute far more to the iron load than the tightly-complexed iron in meat. Much of the inorganic iron in food consists of iron salts added in the fortification of flour and cereals, and it may be of value to explore the possibility of feeding these children with suitable flour and cereal products which have not been enriched with iron. In addition, it is evident that the iron load in these children will increase rapidly when unwary physicians prescribe iron for them. It is of great importance that longterm treatment with iron should only be given when it is certain that the anaemia is due to iron deficiency.

There is also good evidence that the amount of iron absorbed is less when anaemic patients are transfused (Erlandson et al., 1962; Schiffer et al., 1965). This appears to be due to the correction of the anaemia, and also in some patients to the decrease in erythropoiesis which follows transfusion. The practice of restricting transfusion to a minimum may, therefore, contribute to an increase in alimentary iron absorption, although the accumulation of iron from transfused blood will be reduced. In most instances the quantity of iron accumulated through transfusions is greater, but the possibility remains that iron absorbed from the intestine may be more harmful, due to immediate parenchymal deposition. These anaemic children may also grow and develop more rapidly, and have fewer infections, if maintained at a minimum haemoglobin level of $8 \mathrm{~g} . / 100 \mathrm{ml}$. by frequent transfusions (Wolman, 1964). Now that the consequent increased iron deposition can be treated by the use of chelating agents, it seems possible that the advantages of maintaining a high minimum haemoglobin level may outweigh the disadvantages.

In conclusion, it is evident that iron overload can now be treated by the removal of excess iron with 
chelating agents. To be successful, this needs massive doses, and most probably a schedule involving daily injections. This seems well worth while in patients with marked iron loading, where some subjective and objective improvement, and possibly prolonged survival, may be expected. It has not yet been shown that prophylactic administration of chelating agents is of any value in preventing iron accumulation, though the effect of desferrioxamine on haem synthesis in some refractory anaemias deserves further study, and effective means have still to be found to block the absorption of food iron. Useful as they are, it is to be hoped that the existing chelating agents will eventually be supplemented by others that can be given by mouth.

Part of this work was carried out during tenure of a Research Fellowship supported by the Joint Research Board of the Institute of Child Health, London University, and The Hospital for Sick Children, Great Ormond Street, London.

\section{REFERENCES}

Amerman, E. E., Brescia, M. A., and Aftahi, F. (1958). Ferrous sulfate poisoning. J. Pediat., 53, 476.

Ascham, L., Speirs, M., and Maddox, D. (1938). The availability of iron in various foods. J. Nutr., 16, 425.

Badenoch, J., and Callender, S. T. (1954). Iron metabolism in steatorrhea. The use of radioactive iron in studies of absorption and utilization. Blood, 9, 123.

- , and - (1960). Effect of corticosteroids and gluten-free diet on absorption of iron in idiopathic steatorrhoea and coeliac disease. Lancet, 1, 192.

Baird, I. McL., Podmore, D. A., and Wilson, G. M. (1957). Changes in iron metabolism following gastrectomy and other surgical operations. Clin. Sci., 16, 463.

Bannerman, R. M., Callender, S. T., Hardisty, R. M., and Smith, R. S. (1964). Iron absorption in thalassaemia. Brit. J. Haemat., 10, 490.

, -, and Williams, D. L. (1962). Effect of desferrioxamine and D.T.P.A. in iron overload. Brit. med. J., 2, 1573.

- and Malpas, J. S. (1965). Studies on desferrioxamine in relation to the absorption of iron. Brit. J. Haemat., 11, 15.

Basu, S. K. (1963). Rapid administration of iron-dextran in late pregnancy. Lancet, 1, 1430.

Bergeim, O., and Kirsch, E. R. (1949). Reduction of iron in the human stomach. J. biol. Chem., 177, 591.

Beutler, E. (1964). Tissue effects of iron deficiency. In Iron Metabolism, an International Symposium, ed. F. Gross. Springer, Berlin.

—_, Larsh, S. E., and Gurney, C. W. (1960). Iron therapy in chronically fatigued, nonanemic women: a double-blind study. Ann. intern. Med., 52, 378.

$\longrightarrow$, Robson, M. J., and Buttenwieser, E. (1958). A comparison of the plasma iron, iron-binding capacity, sternal marrow iron and other methods in the chemical evaluation of iron stores. ibid., 48, 60 .

Biggs, J. C., and Davis, A. E. (1963). Relationship of diminished pancreatic secretion to haemochromatosis. Lancet, 2, 814.

Bothwell, T. H., and Finch, C. A. (1962). Iron Metabolism. Little, Brown, Boston.

, Pirzio-Biroli, G., and Finch, C. A. (1958). Iron absorption. I. Factors influencing absorption. J. Lab. clin. Med., 51, 24.

Bourne, M. S., Elves, M. W., and Israëls, M. C. G. (1965). Familial pyridoxine-responsive anaemia. Brit. J. Haemat., 11, 1.

Boyle, D., Dellipiani, A. W., Owen, J. A., Seaton, D. A., and Tonkin, R. W. (1964). Black urine after 'jectofer' injections. Brit. med. J., $1,285$.

Briggs, J. D., Kennedy, A. C., and Goldberg, A. (1963). Urinary white-cell excretion after iron-sorbitol-citric-acid. ibid., 2, 352.
Brise, H., and Hallberg, L. (1962). Iron absorption studies. A method for comparative studies on iron absorption in man using two radioiron isotopes. II. Acta med. scand., 171, Suppl. 376, 7.

Brit.med.J.(1963). To-day's drugs, Iron. Iron metabolism. 2, 367.

Brokaw, K. F., Sedam, M. S., and Cassirer, A. M. (1942). The influence of diet on the physiologic anemia of infants. J.Pediat., 21, 769.

Brown, E. B., Jr., Dubach, R., and Moore, C. V. (1958). Studies in iron transportation and metabolism. XI. Critical analysis of mucosal block by large doses of inorganic iron in human subjects. J. Lab. clin. Med., 52, 335.

- , and Justus, B. W. (1958). In vitro absorption of radioiron by everted pouches of rat intestine. Amer. J. Physiol., 194, 319.

Callender, S. T. (1964). Digestive absorption of iron. In Iron Metabolism, an International Symposium, ed. F. Gross. Springer, Berlin.

— and Malpas, J. S. (1963). Absorption of iron in cirrhosis of liver. Brit. med. J., 2, 1516.

Cappell, D. F., Hutchison, H. E., and Jowett, M. (1957). Transfusional siderosis: the effects of excessive iron deposits on the tissues. J. Path. Bact., 74, 245.

Cavell, P. A., and Widdowson, E. M. (1964). Intakes and excretions of iron, copper, and zinc in the neonatal period. Arch. Dis. Childh., 39, 496.

Chodos, R. B., Ross, J. F., Apt, L., Pollycove, M., and Halkett, J. A. E. (1957). The absorption of radioiron labeled foods and iron salts in normal and iron-deficient subjects and in idiopathic hemochromatosis. J. clin. Invest., 36, 314.

CIBA (1964). Desferal. A Specific Iron Chelating Agent for the Treatment of Chronic Iron Overload, Acute Iron Poisoning and for Diagnosis. Ciba Laboratories, Horsham.

Clay, B., Rosenberg, B., Sampson, N., and Samuels, S. I. (1965). Reactions to total dose intravenous infusion of iron dextran (imferon). Brit. med. J., 1, 29.

Cleton, F. J., Noyes, W. D., Turnbull, A., and Finch, C. A. (1961). The use of chelates in the treatment of iron overload. Clin. Res., 9,91 .

Coleman, D. H., Stevens, A. R., Jr., Dodge, H. T., and Finch, C. A. (1953). Rate of blood regeneration after blood loss. Arch. intern. Med., 92, 341.

Conrad, M. E., Jr., and Crosby, W. H. (1963). Intestinal mucosal mechanisms controlling iron absorption. Blood, 22, 406.

Covey, T. J. (1964). Ferrous sulfate poisoning. J. Pediat., 64, 218.

Crosby, W. H. (1963). The control of iron balance by the intestinal mucosa. Blood, 22, 441.

—, Conrad, M. E., Jr., and Wheby, M. S. (1963). The rate of iron accumulation in iron storage disease. ibid., 22, 429.

Davidson, L. S. P., Donaldson, G. M. M., Dyar, M. J., Lindsay, S. T., and McSorley, J. G. (1942). Nutritional iron deficiency anaemia in wartime. Part I. The haemoglobin levels of 831 infants and children. Brit. med. J., 2, 505.

Davidson, S., and Passmore, R. (1963). Human Nutrition and Dietetics, 2nd ed. Livingstone, Edinburgh.

Davis, A. E., and Badenoch, J. (1962). Iron absorption in pancreatic disease. Lancet, 2, 6.

Davis, L. R., Marten, R. H., and Sarkany, I. (1960). Iron-deficiency anaemia in European and West Indian infants in London. Brit. med. J., 2, 1426.

Dowdle, E. B., Schachter, D., and Schenker, H. (1960). Active transport of $\mathrm{Fe}^{59}$ by everted segments of rat duodenum. Amer. J. Physiol., 198, 609.

Drabkin, D. L. (1951). Metabolism of the hemin chromoproteins. Physiol. Rev., 31, 345.

Dubach, R., Moore, C. V., and Callender, S. T. (1955). Studies in iron transportation and metabolism. IX. The excretion of iron as measured by the isotope technique. J. Lab. clin. Med., 45, 599.

Elliott, W. D. (1962). The prevention of anaemia of prematurity. Arch. Dis. Childh., 37, 297.

Ellis, J. T., Schulman, I., and Smith, C. H. (1954). Generalized siderosis with fibrosis of liver and pancreas in Cooley's (Mediterranean) anemia, with observations on the pathogenesis of the siderosis and fibrosis. Amer. J. Path., 30, 287.

Engle, M. A. (1964). Cardiac involvement in Cooley's anemia. Ann. N.Y. Acad. Sci., 119, 694.

Erlandson, M. E., Walden, B., Stern, G., Hilgartner, M. W., Wehman, J., and Smith, C. H. (1962). Studies on congenital hemolytic syndromes. IV. Gastrointestinal absorption of iron. Blood, $19,359$. 
Fahey, J. L., Rath, C. E., Princiotto, J. V., Brick, I. B., and Rubin, M. (1961). Evaluation of trisodium calcium diethylenetriaminepentaacetate in iron storage disease. J. Lab. clin. Med., 57, 436.

Farquhar, J. D. (1963). Iron supplementation during first year of life. Amer. J. Dis. Child., 106, 201.

Fielding, J. (1962). Sarcoma induction by iron-carbohydrate complexes. Brit. med.J., 1, 1800 .

Finch, C. A. (1959). Body iron exchange in man. J. clin. Invest., 38, 392.

Finch, S., Haskins, D., and Finch, C. A. (1950). Iron metabolism. Hematopoiesis following phlebotomy. Iron as a limiting factor. ibid., 29, 1078.

Fink, H. (1964). Transfusion hemochromatosis in Cooley's anemia. Ann. N.Y. Acad. Sci., 119, 680.

Gabrio, B. W., and Salomon, K. (1950). Distribution of total ferritin in intestine and mesenteric lymph nodes of horses after iron feeding. Proc. Soc. exp. Biol. (N.Y.), 75, 124.

Gairdner, D., Marks, J., and Roscoe, J. D. (1952). Blood formation in infancy. Part II. Normal erythropoiesis. Arch. Dis. Childh., 27, 214.

Gaisford, W., and Jennison, R. F. (1955). Intramuscular iron in infancy. Brit. med. J., 2, 700.

Garby, L., and Sjölin, S. (1959). Absorption of labelled iron in infants less than three months old. Acta paediat. (Uppsala), 48, Suppl. 117, 24.

_ and Vuille, J. C. (1963). Studies on erythro-kinetics in infancy. III. Disappearance from plasma and red-cell uptake of radio-active iron injected intravenously. ibid., 52, 537.

Giblett, E. R., Coleman, D. H., Pirzio-Biroli, G., Donohue, D. M., Motulsky, A. G., and Finch, C. A. (1956). Erythrokinetics: quantitative measurements of red cell production and destruction in normal subjects and patients with anemia. Blood, 11, 291.

Girdwood, R. H. (1952). Treatment of anaemia. Brit. med. J., 1 , 599.

Goldberg, A., Lochhead, A. C., and Dagg, J. H. (1963). Histaminefast achlorhydria and iron absorption. Lancet, 1, 848.

Goldthorp, W. O., Spencer, D., and Dawson, D. W. (1965). Reactions to intravenous iron dextran. Brit. med. J., 1, 316.

Gorten, M. K., Hepner, R., and Workman, J. B. (1963). Iron metabolism in premature infants. I. Absorption and utilization of iron as measured by isotope studies. J. Pediat., 63, 1063.

Granick, S. (1946). Protein apoferritin and ferritin in iron feeding and absorption. Science, 103, 107.

Grimes, A. J., and Hutt, M. S. R. (1957). Metabolism of ${ }^{59} \mathrm{Fe}-$ dextran complex in human subjects. Brit. med. J., 2, 1074.

Groen, J., Van Den Broek, W. A., and Veldman, H. (1947). Absorption of iron compounds from the small intestine in the rat. Biochem. biophys. Acta (Amst.), 1, 315.

Guest, G. M., and Brown, E. W. (1957). Erythrocytes and hemoglobin of the blood in infancy and childhood. III. Factors in variability, statistical studies. A.M.A. Amer. J. Dis. Child., 93, 486.

Haddow, A., and Horning, E. S. (1960). On the carcinogenicity of an iron-dextran complex. J. nat. Cancer Inst., 24, 109.

Hahn, P. F., Bale, W. F., Ross, J. F., Balfour, W. M., and Whipple, G. H. (1943). Radioactive iron absorption by gastro-intestinal tract. Influence of anemia, anoxia and antecedent feeding. Distribution in growing dogs. J. exp. Med., 78, 169.

Hallberg, L., and Sölvell, L. (1960). Iron absorption during constant intragastric infusion of iron in man. Acta med. scand., 168, Suppl. 358, 43.

Heilmeyer, L., Keller, W., Vivell, O., Keiderling, W., Betke, K., Wöhler, F., and Schultze, H. E. (1961). Congenital transferrin deficiency in a seven-year-old girl. Germ. med. Mth., 6, 385.

- , and Wöhler, F. (1963). The treatment of haemochromatosis with desferrioxamine. ibid., 8, 133.

Henderson, F., Vietti, T. J., and Brown, E. B. (1963). Desferrioxamine in the treatment of acute toxic reaction to ferrous gluconate. J. Amer. med. Ass., 186, 1139.

Hoag, M. S., Wallerstein, R. O., and Pollycove, M. (1961). Occult blood loss in iron deficiency anemia of infancy. Pediatrics, 27, 199.

Hwang, Y. F., and Brown, E. B. (1965). Effect of desferrioxamine on iron absorption. Lancet, 1, 135.

Jacobziner, H., and Raybin, H. W. (1962). Iron intoxication. N.Y. St. J. Med., $62,85$.

Kerr, D. N. S., and Davidson, S. (1958). Gastrointestinal intolerance to oral iron preparations. Lancet, 2, 489.
Korman, S. (1960). Iron metabolism in man. Ann. N.Y. Acad. Sci., 88, 460.

Lloyd, J. K., and Brown, G. A. (1964). Homozygous thalassaemia in an English child. Arch. Dis. Childh., 39, 625.

MacGibbon, B. H., and Mollin, D. L. (1965). Sideroblastic anaemia in man: observations on seventy cases. Brit. J. Haemat., 11, 59.

Mackay, H. M. M. (1931). Nutritional anaemia in infancy with special reference to iron deficiency. Spec. Rep. Ser. med. Res. Coun. (Lond.), 157, 65.

Marchasin, S., and Wallerstein R. O. (1964). The treatment of irondeficiency anemia with intravenous iron dextran. Blood, $23,354$.

McCance, R. A., Edgecomb, C. N., and Widdowson, E. M. (1943). Phytic acid and iron absorption. Lancet, 2, 126.

, and Widdowson, E. M. (1937). Absorption and excretion of iron. ibid., 22, 680.

, and - (1951). The metabolism of iron during suckling. J. Physiol. (Lond.), 112, 450.

Mendel, G. A. (1961). Studies on iron absorption. I. The relationships between the rate of erythropoiesis, hypoxia and iron absorption. Blood, 18, 727.

_- Weiler, R. J., and Mangalik, A. (1963). Studies on iron absorption. II. The absorption of iron in experimental anemias of diverse etiology. ibid., 22, 450 .

Mereu, I., and Tonz, O. (1962). The treatment of iron deficiency anaemia in children with iron polyisomaltosate. Germ. med. Mth., 7, 82.

Moe, P. J.' (1963). Iron requirements in infancy. Longitudinal studies of iron requirements during the first year of life. Acta paediat. (Uppsala), Suppl. 150.

- (1964). Iron requirements in infancy. II. The influence of iron-fortified cereals given during the first year of life, on the red blood picture of children at $1 \frac{1}{2}-3$ years of age. ibid., 53, 423 .

Moeschlin, S., and Schnider, U. (1963). Treatment of primary and secondary hemochromatosis and acute iron poisoning with a new potent iron-eliminating agent (desferrioxamine-B). New Engl.J. Med., 269, 57.

Moore, C. V. (1955). The importance of nutritional factors in the pathogenesis of iron-deficiency anemia. Amer.J. clin. Nutr., 3,3 . Bierman, H. Q., Minnich, V., and Arrowsmith, W. R. (1940). Studies in iron absorption with special reference to the relationship of iron metabolism to ascorbic acid. In Blood, Heart, and Circulation, ed. F. R. Moulton (Amer. Assoc. Advanc. Sci. Publ. No. 13). Science Press, Lancaster, Pa.

, and Dubach, R. (1951). Observations on the absorption of iron from foods tagged with radioiron. Trans. Ass. Amer. Phycns, 64, 245.

, and - (1956). Metabolism and requirements of iron in the human. J. Amer. med. Ass., $162,197$.

-, Minnich, V., Vilter, R. W., and Spies, T. D. (1943). Hypochromic anemia in patients with deficiency of the vitamin B complex; response to iron therapy with and without yeast. ibid., 121, 245.

Muller-Eberhard, U., Erlandson, M. E., Ginn, H. E., and Smith, C. H. (1963). Effect of trisodium calcium diethylenetriaminepentaacetate on bivalent cations in thalassemia major. Blood, 22, 209.

Nielsen, J. B. (1963). Influence of desferrioxamine on the renal excretion of iron. Acta med. scand., 173, 499.

Niccum, W. L., Jackson, R. L., and Stearns, G. (1953). Use of ferric and ferrous iron in the prevention of hypochromic anemia in infants. Amer.J. Dis. Child., 86, 553.

Norman, C. S. (1964). The treatment of iron overload with desferrioxamine B. Irish J. med. Sci., 13.

Ohlsson, W. T. L., Kullendorff, G. T., and Ljungberg, L. K. (1953). Transfusion hemosiderosis. Report of a case treated with BAL. Acta. med. scand., 145, 410 .

Oliver, R. A. M. (1959). Siderosis following transfusions of blood. J. Path. Bact., 77, 171.

Pirzio-Biroli, G., Bothwell, T. H., and Finch, C. A. (1958). Iron absorption. II. The absorption of radioiron administered with a standard meal in man. J. Lab. clin. Med., 51, 37.

$\longrightarrow$, and Finch, C. A. (1960). Iron absorption. III. The influence of iron stores on iron absorption in the normal subject. ibid., 55, 216.

Powell, L. W., and Dugdale, A. E. (1964). Desferrioxamine and iron. Lancet, 1, 934.

Powell, R. (1963). Iron-dextran: total-dose infusion technique. ibid., 2, 252. 
Pringle, A., Goldberg, A., Macdonald, E., and Johnston, S. (1962). ${ }^{69} \mathrm{Fe}$ iron sorbitol cirtic-acid complex in iron-deficiency anaemia. ibid., 2, 749.

Richmond, H. G. (1959). Induction of sarcoma in the rat by irondextran complex. Brit. med. J., 1, 947.

Riley, I. D. (1960). Absorption of radioactive iron by anaemic infants. Arch. Dis. Childh., 35, 355.

Robertson, E. F., Maxwell, G. M., and Elliott, R. B. (1963). Studies in thalassaemia major. Med. J. Aust., 2, 705.

Ross, F. G. M. (1953). Pyloric stenosis and fibrous stricture of the stomach due to ferrous sulphate poisoning. Brit. med.J., 2, 1200.

Sanford, R. (1961). The effect of enzymic digestion of foods on the liberation of iron. Aust. Ann. Med., 10, 288.

Schiffer, L. M., Price, D. C., and Cronkite, E. P. (1965). Iron absorption and anemia. J. Lab. clin. Med., 65, 316.

Schulz, J., and Smith, N. J. (1958a). A quantitative study of the adsorption of food iron in infants and children. Amer. J. Dis. Child., 95, 109.

$\longrightarrow$, and - (1958b). Quantitative study of the absorption of iron salts in infants and children. ibid., 95, 120.

Scott, J. M. (1963). Iron-sorbitol-citrate in pregnancy anaemia. Brit. med. J., 2, 354.

Seip, M. (1955). The reticulocyte level, and the erythrocyte production judged, from reticulocyte studies in newborn infants during the first week of life. Acta paediat. (Uppsala), 44, 355.

Seven, M. J., Gottlieb, H., Israel, H. L., Reinhold, J. G., and Rubin, M. (1954). N-hydroxyethylethylenediamine triacetic acid, Versenol in the treatment of hemochromatosis. Amer. J. med. Sci., 228, 646.

Shahidi, N. T., Nathan, D. G., and Diamond, L. K. (1964). Iron deficiency anemia associated with an error of iron metabolism in two siblings. J. clin. Invest., 43, 510.

Shepherd, J. A. (1955). Ferrous sulphate poisoning with gross stricture of the stomach. Brit. med. J., 2, 418.

Sisson, T. R. C., and Lund, C. J. (1957). The influence of maternal iron-deficiency on the newborn. Amer. J. Dis. Child., 94, 525.

Smith, C. A., Caton, W. L., Roby, C. C., Reid, D. E., Caswell, R. S., and Gibson, J. G., II (1950). Transplacental iron; its persistence during infancy as studied isotopically. ibid., 80, 856.

Smith, M. D., and Pannacciulli, I. M. (1958). Absorption of inorganic iron from graded doses; its significance in relation to iron absorption tests and the 'mucosal block' theory. Brit. J. Haemat., 4, 428.

Smith, R. S. (1962). Iron excretion in thalassaemia major after administration of chelating agents. Brit. med. J., 2, 1577. (1964a). Iron absorption in cystic fibrosis. ibid, 1, 608 . (1964b). Chelating agents in the diagnosis and treatment of iron overload in thalassemia. Ann. N.Y. Acad. Sci., 119, 776.

Steiner, M., Baldini, M., and Dameshek, W. (1964). Enzymatic defects of heme synthesis in thalassemia. ibid., 119, 548.

Steinkamp, R., Dubach, R., and Moore, C. V. (1955). Studies in iron transportation and metabolism. VIII. Absorption of radioiron from iron-enriched bread. Arch. intern. Med., 95, 181.

Stevens, A. R., Jr., Pirzio-Biroli, G., Harkins, H. N., Nyhus, L. M., and Finch, C. A. (1959). Iron metabolism in patients after partial gastrectomy. Ann. Surg., 149, 534.

Stott, G. (1960). Anaemia in Mauritius. Bull. Wld Hlth Org., 23, 781.

Stransky, E., and Dauis-Lawas, D. F. (1948). On iron deficiency anemia in infancy and childhood in the tropics. Ann. paediat. (Basel), 171, 139.

Struass, M. B. (1933). Anemia of infancy from maternal iron deficiency in pregnancy. J. clin. Invest., 12, 345.
Sturgeon, P. (1954). Studies of iron requirements in infants and children. I. Normal values for serum iron, copper and free erythrocyte protoporphyrin. Pediatrics, 13, 107.

- (1956). Iron metabolism. A review with special consideration of iron requirements during normal infancy. ibid., 18, 267.

(1958). Studies of iron requirements in infants and children. IV. Recommended daily dietary allowances. In Iron in Clinical Medicine, ed. R. O. Wallerstein, and S. R. Mettier. University of California Press, Berkeley.

- (1959). Studies of iron requirements in infants. III. Influence of supplemental iron during normal pregnancy on mother and infant. B. The infant. Brit. J. Haemat., 5, 45.

Taylor, J., Stiven, D., and Reid, E. W. (1935). Experimental and idiopathic siderosis in cats. J. Path. Bact., 41, 397.

Turnbull, A., Cleton, F., and Finch, C. A. (1962). Iron absorption. IV. The absorption of hemoglobin iron. J. clin. Invest., 41, 1897.

Vahlquist, B., Neander, G., and Neander, E. (1945). Studies on the absorption of iron. I. Absorption of iron from the stomach. Acta paediat. (Uppsala), 32, 768.

Venkatachalam, P. S., Brading, I., George, E. P., and Walsh, R. J. (1956). An experiment in rats to determine whether iron is absorbed only in the ferrous state. Aust. J. exp. Biol. med. Sci., $34,389$.

Verloop, M. C., Meeuwissen, J. E. Th., and Blokhuis, E. W. M. (1958). Comparison of the 'iron absorption test' with the determination of the iron-binding capacity of serum in the diagnosis of iron deficiency. Brit. J. Haemat., 4, 70.

Vischer, E. (1961). Chemistry of desferrioxamine B. In Experience to Date with Desferrioxamine in the Treatment of Diseases Involving a Pathological Deposition of Iron in the Organism. Report (compiled by Dr. P. Imhof, Ciba, Basle) on a meeting of clinical investigators.

Wetherley-Mein, G., Buchanan, J. C., Glass, U. H., and Pearce, L. C. (1962). Metabolism of ${ }^{59} \mathrm{Fe}$-sorbitol complex in man. Brit. med. J., 1, 1796.

Wheby, M. S., and Jones, L. G. (1963). Role of transferrin in iron absorption. J. clin. Invest., 42, 1007.

Whipple, G. A., Sisson, T. R. C., and Lund, C. J. (1957). Delayed ligation of the umbilical cord. Obstet. and Gynec., 10, 603.

Whitehead, R., Carter, R. L., and Sharp, A. A. (1965). Anaemia in occult intestinal malabsorption. J. clin. Path., 18, 110.

Whitten, C. F., Gibson, G., Good, M., and Goodwin, J. F. (1964). Experiences with desferrioxamine in the treatment of acute iron poisoning. J. Pediat., 65, 1050.

Wilson, J. F., Heiner, D. C., and Lahey, M. E. (1962). Studies on iron metabolism. I. Evidence of gastrointestinal dysfunction in infants with iron deficiency anemia: a preliminary report. J. Pediat., 60, 787.

Wintrobe, M. M. (1961). Clinical Hematology, 5th ed. Lea and Febiger, Philadelphia.

Witzleben, C. L., and Wyatt, J. P. (1961). The effect of long survival on the pathology of thalassaemia major. J. Path. Bact., 82, 1.

Wöhler, F. (1961). Clinical and experimental results with desferrioxamine. In Experience to Date with Desferrioxamine in the Treatment of Diseases Involving a Pathological Deposition of Iron in the Organism. Report (compiled by Dr. P. Imhof, Ciba, Basle) on a meeting of clinical investigators.

- (1963). The treatment of haemochromatosis with desferrioxamine. Acta haemat. (Basel), 30, 65.

Wolman, I. J. (1964). Transfusion therapy in Cooley's anemia: growth and health as related to long-range hemoglobin levels. A progress report. Ann. N.Y. Acad. Sci., 119, 736.

Woodruff, C. W., and Bridgeforth, E. B. (1953). Relationship between the hemogram of the infant and that of the mother during pregnancy. Pediatrics, 12, 681 . 